\title{
Community-scale assessment of rooftop-mounted solar energy potential with meteorological, atlas, and GIS data: a case study of Guelph, Ontario (Canada)
}

\author{
Joseph H Mclntyre
}

\begin{abstract}
Background: Forward-thinking governments recognize that local renewable resource use is crucial to the resilience of communities and are developing and implementing community energy plans (CEPs). Guelph, Ontario, (Canada) included solar energy in its CEP, but the question of resource potential remained. The primary goal of this work was the assessment of Guelph's solar energy potential with arrays of grid-tied, rooftop-mounted photovoltaic (PV) and hot-water (HW) panels.
\end{abstract}

Methods: This work relies on atlas and meteorological data with insolation modeling to evaluate the solar resource and incorporates geographic information system data for rooftop area quantification. The assessment applies the performance characteristics of commercially available PV and HW panels and systems to estimate the upper-limit potential for electricity and hot-water production.

Results: The modeling results closely matched the values provided by two solar resource atlases for multiple orientations and time periods. Extensive modeling led to the development of sunflower diagrams, radial plots representing the variation of insolation on planar surfaces with orientation and inclination. The optimum orientation for annual beam and sky-diffuse insolation occurred at $18^{\circ}$ east of south with a slope of $30^{\circ}$. Deviation from the optimum by $15^{\circ}$ resulted in losses of less than $5 \%$.

Conclusions: Assuming horizontal rooftops, Guelph could provide 1,496 GWh of electricity or 5,360 $\mathrm{GWh}_{\text {[e] }}$ of heat, over $90 \%$ or twice the respective demands for 2005. Including the variation of rooftop orientation and inclination, Guelph could achieve 2,950 GWh of electricity or 10,580 GWh $\mathrm{Ge]}_{\text {ef }}$ of heat, approaching double and quadruple the respective 2005 demands.

Keywords: Local, Urban, Solar, Photovoltaic, Hot water, Energy, Assessment, Sunflower

\section{Background}

The Sun radiates the Earth's surface with more energy in $1 \mathrm{~h}$ than that consumed by human civilization in 1 year [1-3]. The Sun is the ultimate source of most renewable energy resources with solar energy representing a substantial opportunity for use as the foundation of any renewable-based support system. Solar energy technologies harness the incident radiation from the Sun (insolation) to directly or indirectly produce hot water, steam,

Correspondence: jmcint03@uoguelph.ca

School of Engineering, University of Guelph, Guelph, Ontario N1G 2W1, Canada and/or electricity. These technologies include a range of commercially available photovoltaic (PV) and hot-water (HW) devices that rely on direct, diffuse, and/or concentrated sunlight. The popularity of these devices continues to grow along with support for the use of rooftopmounted solar panels in communities, as evidenced by recent legislation [4-9].

Forward-thinking communities are developing and implementing community energy plans (CEPs) as their use gains value in urban and regional planning [10]. These plans lay out long-term strategies and goals for future energy availability with respect to location,

\section{至}


population, and commerce [11] that embrace, prioritize, and balance economic, environmental, and social considerations. CEPs stand as targets that communities work toward to ensure that supply and demand remain in sync with quality-of-life aspirations. Some CEPs incorporate demand reduction strategies that increase energy security while reducing environmental impact [12]. Due to their importance, there are guides available to help communities with plan development from conception through implementation [13-15].

Planning of this nature involves an understanding of the spatial aspects of resources and their use. Geographic information systems (GIS) provide an interface for users to spatially integrate data [16], allowing them to 'view, understand, question, interpret, and visualize... relationships, patterns and trends' [17]. Planners are incorporating GIS for the purpose of evaluating renewable resource potential [18]. There are also a variety of tools that share GIS features and are beneficial to planners. For example, the Canadian Urban Institute develops and provides tools for the spatial analysis of supply and demand [19]. There are also publicly available and interactive solar atlases, like that of Natural Resources Canada (NRCan), which provide local solar resource estimates including the use of various technologies [20]. Community planners can utilize such tools for the assessment of local renewable resources. The assessment of rooftop-mounted solar energy potential combines the spatial aspects of the community with local insolation data and the performance parameters of the technology being considered. The process relies on the availability of data or access to technology for its acquisition, without which the use of assumptions may be required.

A variety of work exists on the assessment of solar energy for communities. Liu et al. [21] assessed rooftopmounted PV potential for the province of Jiangsu, China $\left(>100,000 \mathrm{~km}^{2}\right)$. Their work utilized the spatial processing capabilities of ArcGIS and incorporated meteorological and satellite-based insolation data with statistical sampling methods for rooftop area estimation. They assumed that all panels faced due south, with an inclination of $40^{\circ}$ and excluded shading effects. Wiginton et al. [22] estimated rooftop-mounted PV potential for a region in the province of Ontario, Canada (approximately $48,000 \mathrm{~km}^{2}$ ). Their work focused on estimating the available rooftop area for the region using per capita statistical methods and digitized building footprint data with the Feature Analyst extension of ArcGIS. Their quantification of the PV panel installation area relied on an approximation of the proportion of flat and inclined rooftops, excluding half of the latter as north facing and $70 \%$ of the total due to shading. The estimation of solar energy potential relied on an annual average of the mean daily global insolation for a horizontal plane. Hofierka and Kaňuk [23] quantified rooftop-mounted PV potential for the city of Bardejov, Slovakia $\left(<5 \mathrm{~km}^{2}\right)$ with opensource GIS modules for insolation and a web-based utility for PV potential estimation. Their study included 3-D modeling of buildings using topographic maps, orthographic images, and large-scale city maps depicting roof type, area, inclination, and orientation, as acquired using light detection and ranging (LiDAR) technology. Furthermore, they categorized buildings according to their use, with variation associated to the applicable rooftop area and insolation as a function of several inclinations and orientations. Their work focused on the city's core, with extension to the remainder of the community based on several assumptions. Similarly, Nguyen and Pearce [24] evaluated 100 buildings in Kingston, Ontario, for performance losses related to terrain and near-surface shading on rooftop-mounted PV systems. Their work yielded an algorithm for the incorporation of shading losses with the use of open-source GIS modules based on data captured with LiDAR. Each of these studies focused on PV potential and took varied approaches for the use and application of rooftop area and solar resource data.

The City of Guelph (Figure 1) is $100 \mathrm{~km}$ westsouthwest of Toronto (Ontario, Canada). The population was 122,000 in 2011 [25], and planners expect that number to reach between 145,000 and 175,000 by 2027 [26]. In 2007, the city approved its CEP [27] which called for energy demand reduction over 25 years while shifting to renewable resources. This plan acknowledged that solar energy could help the city attain these goals. However, an important and hitherto unanswered question remained: what is the potential for solar energy in the city? The objectives of this work were threefold. The primary goal was to assess the solar energy potential for the city with arrays of grid-tied, rooftop-mounted PV and HW panels. This task entailed an evaluation of the local solar resource which became a large component of this objective. The second objective was to make the assessment transferable to other communities. The third was to compare the assessed potential with the city's demand.

This paper presents the strategies and data resources used to assess the potential for solar energy conversion to electricity and heat as components of Guelph's future renewable energy portfolio. This study relied on a solar resource evaluation that utilized data from two solar atlases and one meteorological station, the latter to which we applied two models. The use of multiple data sources allowed for a comparison of resource estimates, while the modeling of meteorological data enabled the investigation of panel orientation and inclination. The estimates of production potential relied on the performance characteristics of commercially available PV and HW panels and systems. In this study, we applied two 


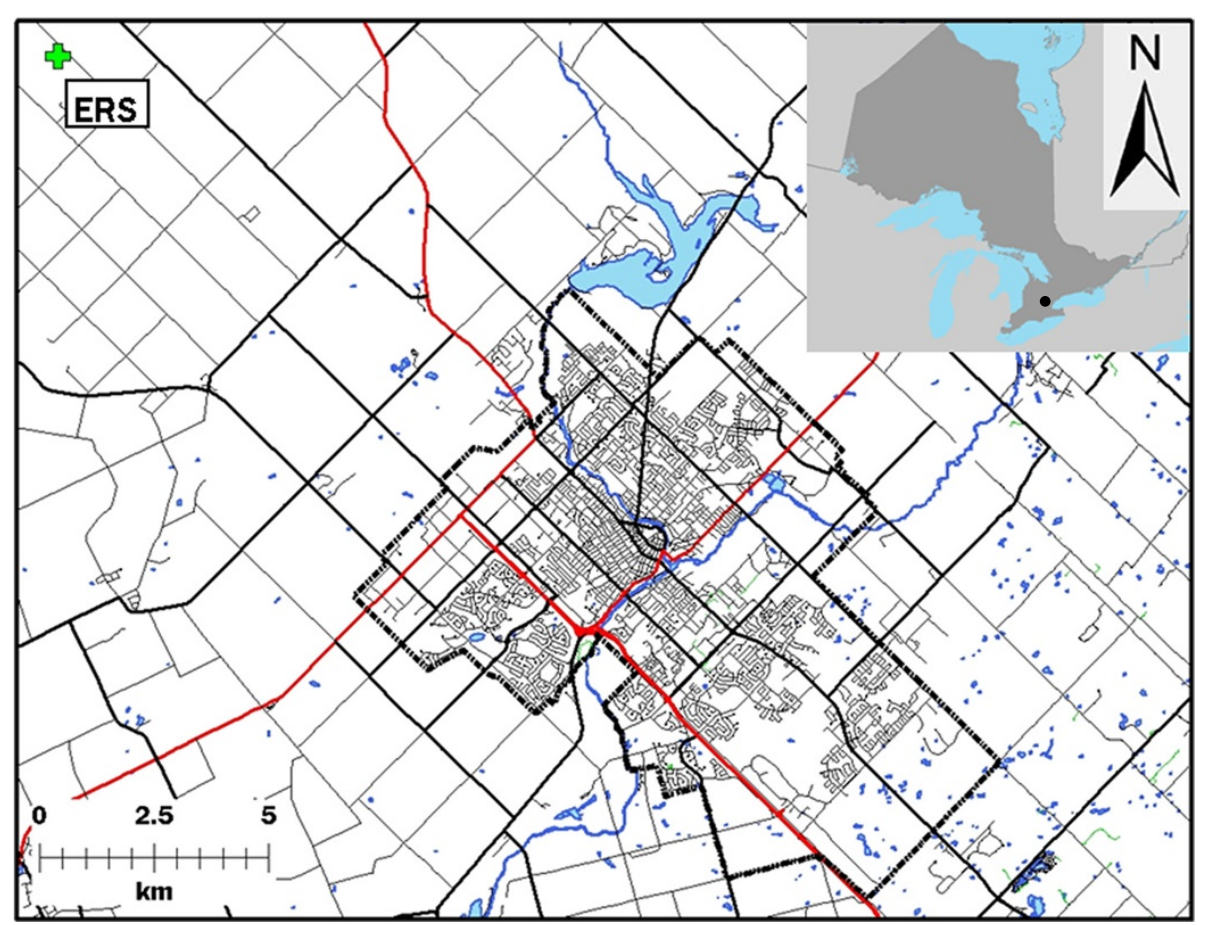

Figure 1 Map of Guelph with the location of the ERS weather station. The relative location (dot) of the city in Ontario, Canada.

strategies for estimating the production potential with rooftop-mounted arrays. The strategies revolved around two mounting scenarios for the respective arrays, both of which relied on GIS data, including building footprint values and zoning classifications. The assessment involved several combinations of solar resource results with the performance of the respective arrays based on these scenarios. This paper concludes with a comparison of the results of this estimate with the total energy, electricity, and heat demands of Guelph for 2005.

\section{Methods}

Figure 2 shows the sequence of application for the methods and models used to estimate the solar energy potential in and for Guelph. We obtained insolation data from a local meteorological station and two solar atlases as detailed in the relating sections. The 'Solar PV system' and 'Solar HW system' sections provide the performance of the respective panels and balance of systems (BOSs). A variety of models exist for the evaluation of insolation on surfaces as a function of orientation and tilt, each

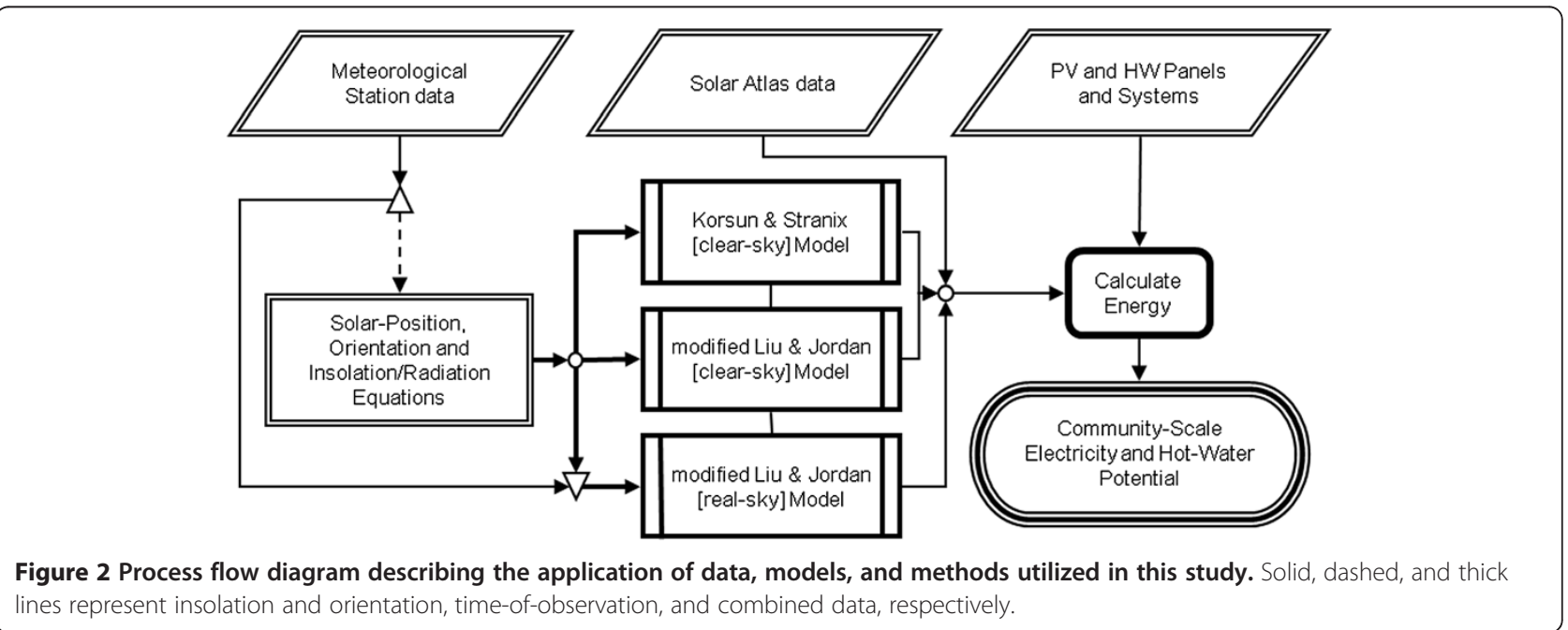


varying with regard to application and complexity (e.g., sky-diffuse insolation component) [28-33]. This study incorporated two such models, with the use of solar position and orientation correlations and approximations of extraterrestrial irradiation. The first model, that of Korsun and Stranix [34] (K\&S), estimates the direct and sky-diffuse irradiation with simulated insolation data. The second is a modified version of the model of Liu and Jordan [35] (mL\&J) which estimates the direct, skydiffuse, and ground-reflected irradiation with observed insolation data. As shown in Figure 2, we also utilized a simulated insolation variant of the mL\&J model. We differentiate the models based on the use of observed insolation data, with their inclusion described as approximating the conditions of a 'real sky' and their exclusion providing that of a 'clear sky.' The 'Application of the models' section provides additional details regarding the use of these models in this study. The calculation of the energy potential resulted from the multiplication of the insolation (atlas or model) with the performance of the respective systems. The subsequent calculation of the potential from rooftop-mounted arrays relied on GIS data including building footprint and zoning characterization. The 'Assessment strategies for community-scale potential' section describes the combination of the data and results from modeling for the estimation of community-scale potential.

\section{Meteorological station data}

The use of meteorological data allows the greatest flexibility in terms of the quantification of solar energy potential with respect to orientation but requires the most work for its application. The Department of Plant Agriculture at the University of Guelph operates several weather stations including the Elora Research Station (ERS), which lies in open agricultural fields $15 \mathrm{~km}$

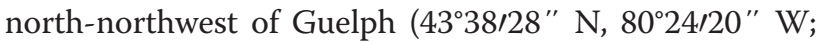
Figure 1) [36]. The facility is maintained according to Environment Canada standards for weather station monitoring, with insolation data measured with a Kipp \& Zonen CM-5 pyranometer (Delft, The Netherlands) [37]. The department hosts a web-based repository, which provides 1-h average insolation as recorded with the year, Julian calendar day, and end-of-hour (standard) time [37]. We acquired data from this repository and applied those for the 21-year period spanning from January 1989 through December 2009. The department's data management team denoted erratic data, and we assumed the validity of the remainder with the exception and exclusion of negative and duplicated values. Our use of these data relied on the conclusion of Cros et al., who reported the validity of applying solar irradiation data to sites within a $30-\mathrm{km}$ radius [38].

\section{Solar atlas data}

NRCan provides a publicly available database called the Photovoltaic Potential and Solar Resource Maps of Canada [20]. Pelland et al. [39] described the development of this resource along with a variety of its details. The developers modeled monthly mean daily global insolation data for the period between 1974 and 1993 to create solar resource maps that provided monthly and annual values. Their work resulted in this web-based navigable map that provides PV potential and mean daily global insolation values with a resolution of $10 \mathrm{~km}$ (300 arc sec). The maps of PV potential display results for four south-facing slopes: latitude, $15^{\circ}$ less than latitude, $15^{\circ}$ more than latitude, and $90^{\circ}$ (vertical). The mean daily global insolation values include two additional results for horizontal and two-axis solar-tracking surfaces. Pelland et al. applied a performance ratio (PR), 'the ratio of actual system yield $(\mathrm{kWh} / \mathrm{kW})$ to the reference or nominal yield,' of 0.75 [39] based on the work of the International Energy Agency [40].

Prior to the development of this resource, the Ministry of Energy, Mines and Resources (now part of NRCan) provided a solar insolation reference with the National Atlas of Canada [41]. The 5th edition of the atlas (1984) included five sets of maps that represented annual and monthly (December, June, April, and October) solar irradiation based on observations from 1956 to 1978 . These maps included mean daily global solar irradiation and variability $\left(\mathrm{MJ} / \mathrm{m}^{2}\right)$ for a horizontal surface as well as irradiation values for south-facing surfaces inclined at $60^{\circ}$ and $90^{\circ}$. Throughout the remainder of this paper, we refer to these as the NRCan Interactive Maps and $\mathrm{Na}$ tional Atlas, respectively.

\section{Solar PV system}

For this study, we decided to model a commercially available one-sun PV panel with high conversion efficiency. Our review of such panels led to the selection of the E20/327 manufactured by SunPower (San Jose, CA, USA). Company literature indicated that these panels have cell and panel efficiencies of $22.5 \%$ and $20.1 \%$, respectively [42], as rated under standard testing conditions (i.e., $1,000 \mathrm{~W} / \mathrm{m}^{2}$ (one sun), AM 1.5 irradiance spectrum, and cell temperature of $25^{\circ} \mathrm{C}$ ) [42-44]. Panel efficiency depends on insolation and other factors including the ambient and panel temperatures [45], with PV system output known to degrade with time [46] and be impacted by maintenance [47]. For this study, we focused our attention on insolation and excluded the impact of the other factors. We applied an efficiency of $75 \%$ for the PV BOS for grid-tied applications, equivalent to the PR value utilized by Pelland et al. [39] (per the 'Solar atlas data' section) and ignored storage issues. This value represents the mode value of the annual 
average PR from the 'worldwide monitoring of 395 gridconnected PV systems. . built between 1996 and 2002' [39]. The values obtained in that study ranged from 0.4 to 0.85 , with an average of 0.702 [39].

\section{Solar HW system}

There are a variety of commercially available solar HW collectors and several ways to configure such systems. Leidl and Lubitz [48] indicated that HW systems predominantly rely on flat-plate or evacuated-tube panels or reflective concentrators, noting that the first was more common for residential applications. A brief review of such panels led to the selection of the auroTHERM plus VFK 150 manufactured by Vaillant (Remscheid, Germany) [49]. The conversion efficiency of solar collectors varies with design and depends on insolation, the ambient air temperature, and inlet and outlet fluid temperatures. Manufacturers often provide efficiency coefficients that, when applied to an equation, describe the variation of the specific nominal capacity of a collector as a function of the latter three variables [50]. The inability to account for fluid temperature variation for a multitude of systems led to the decision to apply a broad-range efficiency of $60 \%$. The BOS components and system installation could also vary with application, and, as such, we assumed a blanket BOS efficiency of $90 \%$. We ignored transmission and storage issues and assumed that the energy would be used at the collection point or transferred for local use.

\section{City of Guelph GIS data}

This solar energy assessment for the City of Guelph utilized the assumption that the solar panels would be rooftop-mounted on existing buildings. We utilized the most recent data available from the City of Guelph [51] and acquired building footprint values by assembling a GIS map using ESRI ArcMap [52]. The City of Guelph data included building footprints and zoning characterization [53] which indicated the types of buildings present. The zoning and subsequent building categorizations were commercial, industrial, institutional, residential, agricultural and aggregate, and park and open spaces. We accepted these data as provided and these became the basis for scaling the size of the community arrays.

\section{Solar position, orientation, and extraterrestrial irradiation/ insolation equations}

Multiple correlations exist for the calculation of the angular position of the Sun with respect to the orientation of and the corresponding extraterrestrial irradiation on a surface of interest [54]. This section provides the two correlations which we applied to the models described in the following sections. Figure 3 shows the angles of orientation for a tilted plane relative to due south (northern hemisphere) and a horizontal plane on the Earth's surface. The corresponding angles of orientation are the azimuth angle, $\gamma$ (south $0^{\circ}$; west positive), and surface slope (incline or tilt), $\beta$ (horizontal $0^{\circ}$, vertical $90^{\circ}$ ). This figure also shows angles of incidence of beam (direct) solar radiation relative to the surface normal of horizontal and inclined planes on the Earth's surface, $\theta_{\mathrm{z}}$ and $\theta$, respectively.

The angle of incidence, $\theta$, is of primary importance as it describes the angular deviation of the Sun from the normal of an inclined surface. Its calculation depends on the surface slope and azimuth, the site latitude, $\phi$, the declination, and the hour angle:

$$
\begin{aligned}
\cos \theta= & \sin \delta \sin \phi \cos \beta-\sin \delta \cos \phi \sin \beta \cos y \\
& +\cos \delta \cos \phi \cos \beta \cos \omega \\
& +\cos \delta \sin \phi \sin \beta \cos \gamma \cos \omega \\
& +\cos \delta \sin \beta \sin \gamma \sin \omega
\end{aligned}
$$

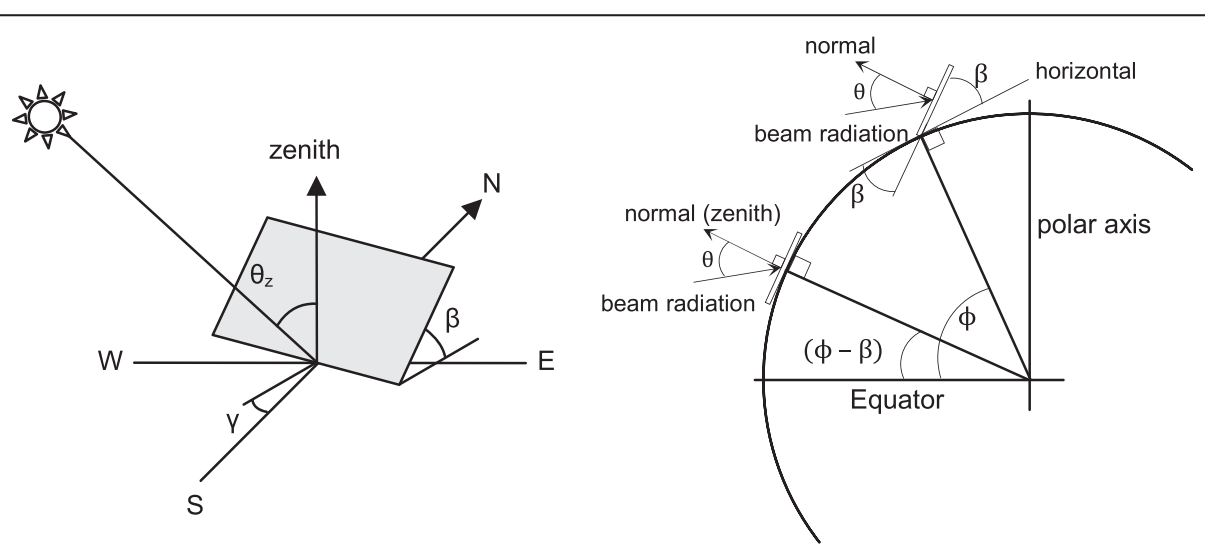

Figure 3 Angles of orientation for a tilted plane and a horizontal plane. (a) The Sun's position related to the Earth's surface and an inclined plane; (b) the relative angles of position between the plane and the Earth's surface. (Adapted from [54]). 
The calculation of $\theta_{\mathrm{z}}$, the zenith, or incidence angle for the horizontal plane relies only on the latitude, declination, and hour angles:

$$
\cos \theta_{z}=\sin \phi \sin \delta+\cos \delta \cos \phi \cos \omega=\frac{1}{\sec \theta_{z}}
$$

The declination, $\delta$, is the angle of the Sun relative to the Earth's equatorial plane and accounts for the axial tilt of the Earth as it orbits the Sun. Cooper [55] provided an empirical correlation that relates its value to the Julian calendar day, $n$ :

$$
\delta=23.45^{\circ} \sin \left(360 \frac{284+n}{365}\right)
$$

Spencer [56] developed a more accurate correlation for the calculation of this, and several solar position angles, by way of Fourier transform [54]:

$$
\begin{aligned}
\delta=\frac{180}{\pi} & (0.006918-0.399912 \cos B+0.070257 \sin B \\
& -0.006758 \cos 2 B+0.000907 \sin 2 B \\
& -0.002679 \cos 3 B+0.00148 \sin 3 B) .
\end{aligned}
$$

Spencer's correlation relies on the parameter $B$, which one calculates as follows:

$$
B=(n-1) \frac{360}{365} \text {. }
$$

The hour (or time) angle, $\omega$, represents the angular displacement of the Sun east or west of the local meridian and accounts for the Earth's rotation about the polar axis. Its value increases by $15^{\circ}$ per hour of solar time, $T_{\mathrm{S}}$, starting at solar noon (i.e., afternoon positive, morning negative):

$$
\omega=15\left(T_{s}-12\right) .
$$

The solar time is an adjustment from the standard time (hour), $h$, that relies on the equation of time, $E$ ( $\mathrm{min}$ ), the local time-zone meridian, $L_{\mathrm{ST}}$, and the site longitude, $L_{\mathrm{LOC}}$ :

$$
T_{s}=h+\frac{\left(4\left(L_{S T}-L_{L O C}\right)+E\right)}{60} .
$$

Spencer's equation of time also utilizes the parameter $B[56]$ :

$$
\begin{aligned}
E= & 229.2(0.000075+0.001868 \cos B-0.032077 \sin B \\
& -0.014615 \cos 2 B-0.04089 \sin 2 B) .
\end{aligned}
$$

Calculation of the sunset angle, $\omega_{\mathrm{s}}$, the hour angle of the Sun at the horizon in the morning, depends on the latitude and declination:

$$
\cos \omega_{s}=-\tan \phi \tan \delta .
$$

The sunrise angle has the negative value of the sunset angle.
The solar position angles allow for the estimation of solar irradiation on surfaces when applied with other correlations. The empirical correlation relating the variation of solar irradiation on a plane normal to the radiation of the Sun, $G_{\mathrm{ON}}$, depends the Julian calendar day, $n$ :

$$
G_{O N}=G_{S C}\left(1+0.033 \cos \left(\frac{360 n}{365}\right)\right) .
$$

Spencer [56] provided an alternative correlation which utilizes the parameter $B$ :

$$
\begin{aligned}
G_{O N}= & G_{S C}(1.000110+0.034221 \cos B \\
& +0.001280 \sin B+0.000719 \cos 2 B \\
& +0.000077 \sin 2 B) .
\end{aligned}
$$

Multiplication of $G_{\mathrm{ON}}$ by $\cos \theta_{\mathrm{z}}$ yields the extraterrestrial irradiation on a horizontal surface, $G_{O}$ :

$$
G_{O}=G_{O N} \cos \theta_{z} .
$$

The integration of Equation 12 between two hour angles yields the extraterrestrial irradiation on a horizontal surface, $I_{0}$, for a specific period during a day [54]:

$$
\begin{aligned}
I_{0}= & \frac{12 \times 3,600}{\pi} G_{O N} \times\left[\left(\cos \phi \cos \delta\left(\sin \omega_{2}-\sin \omega_{1}\right)\right)\right. \\
& \left.+\frac{\pi\left(\omega_{2}-\omega_{1}\right)}{180} \sin \phi \sin \delta\right] .
\end{aligned}
$$

Here, $\omega_{2}$ is greater than $\omega_{1}$ and the respective values represent the end and start of the period. The horizon blocks the Sun's rays during part of the observation period just before sunrise and after sunset. Continuity requires the substitution of $\omega_{1}$ and $\omega_{2}$ with $-\omega_{\mathrm{s}}$ and $\omega_{\mathrm{s}}$, respectively, during these periods when the zenith angle, $\theta_{\mathrm{z}}$, is greater than $90^{\circ}$.

Solar radiation may follow several paths before reaching a surface. Discussion typically includes the direct or beam, the sky-diffuse or scattered, and the groundreflected components shown in Figure 4. The reflection from other surfaces (i.e., adjacent buildings, etc.) at various orientations depends on the situation and is excluded in the modeling described in the following sections.

\section{The K\&S model}

Korsun and Stranix [34] presented a model used to match peak insolation with peak energy demand, a task requiring seasonal changes to the solar panel's azimuth. These authors based their model, in part, on earlier work by Duffie and Beckman [57]. The K\&S model estimates the direct (D) and sky-diffuse (S) insolation on an inclined plane and relies on empirical correlations and constants with the exclusion of solar irradiation observations. This model relies on the equations of Cooper [55] for 


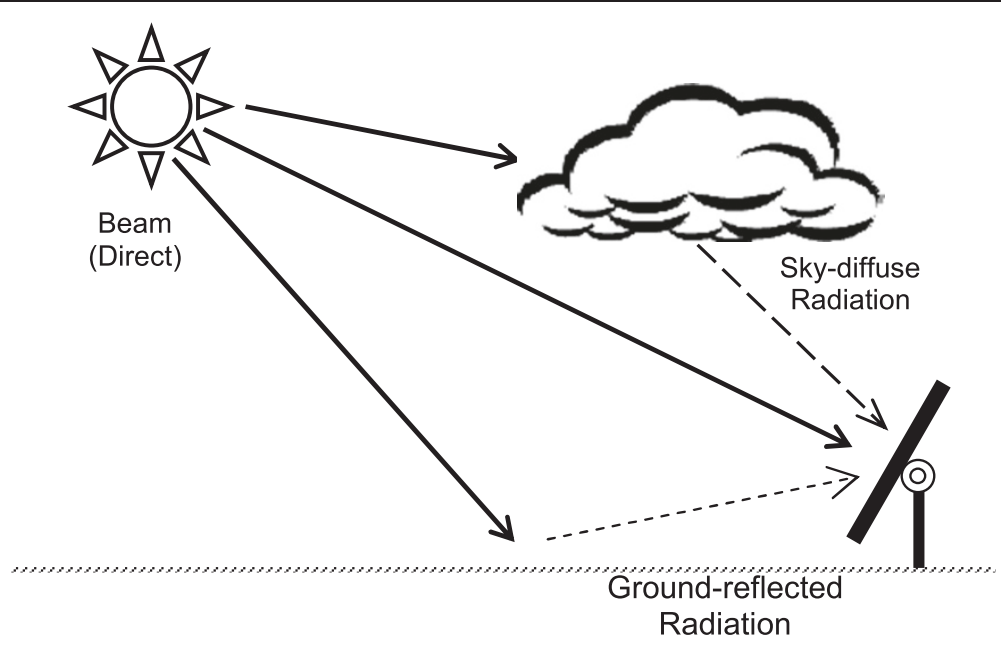

Figure 4 Solar beam (direct), sky-diffuse, and ground-reflected radiation on an inclined planar surface. (Adapted from [61]).

solar position and extraterrestrial irradiation. The first part of the model determines the incidence of solar irradiation on the horizontal plane, $I_{\mathrm{D}+\mathrm{S}}$, at the location of interest:

$$
I_{D+S}=\left(G_{S C}+G_{0 S}\right) e^{-c\left(\sec \theta_{z}\right)^{d}} .
$$

The constants used by Korsun and Stranix [34] for the exoatmospheric flux, $G_{\mathrm{SC}}$, and the apparent solar flux due to scatter, $G_{O S}$, were 1,353 and $214 \mathrm{~W} / \mathrm{m}^{2}$, respectively. The value of the exoatmospheric flux has undergone historic revision with this being the accepted value of $G_{S C}$ at the time of publication $[28,57,58]$. The World Radiation Center more recently adopted the value of $1,367 \mathrm{~W} / \mathrm{m}^{2}$ [54] which we applied to this model. This decision introduced an error of less than $1 \%$. In the K\&S model, the empirical coefficient $c$ and exponent $d$ had values of 0.357 and 0.678 , respectively. Calculation of the beam and sky-diffuse insolation on an inclined surface, $I_{\mathrm{T}, \mathrm{D}}+\mathrm{S}$, occurs via multiplication of insolation on the horizontal plane by $\cos \theta$ :

$$
I_{T, D+S}=\left(I_{D+S}\right) \cos \theta .
$$

\section{The $\mathrm{mL} \& \mathrm{~J}$ model}

Liu and Jordan developed the following model [35] and pioneered the development of correlations for the empirical estimation of the beam and sky-diffuse components of insolation [59]. Pyranometers measure the total solar irradiation (beam and sky-diffuse; $\mathrm{W} / \mathrm{m}^{2}$ ), whereas pyroheliometers only measure the beam irradiation while excluding the sky-diffuse component. Measurement systems typically integrate the total solar irradiation over a period of time and record them as hourly total/global horizontal irradiance or total solar irradiation, $I\left(\mathrm{~J} / \mathrm{m}^{2}\right)$, which varies with atmospheric conditions. Meteorological observations normally exclude the ground-reflected component. The ratio of the observed irradiation to the extraterrestrial irradiation on a horizontal surface (absent of atmospheric conditions), $I_{0}$, is the clearness index, $k_{T}$ :

$$
k_{T}=I / I_{0} .
$$

This index allows for the division of beam and sky-diffuse irradiation via studies that utilize both pyranometer and pyroheliometer data. Although Liu and Jordan provided correlations for several cities [59], we relied on those of Orgill and Hollands [60] which utilized data from the Toronto airport due to its relative proximity. Their study covers the 4-year period between September 1967 and August 1971 and remains in current use [54]. Orgill and Hollands [60] provided three equations for the ratio of the sky-diffuse to total irradiation:

$$
I_{d} / I=\left\{\begin{array}{c}
1.0-0.249 k_{T} \text { for } 0 \leq k_{T}<0.35 \\
1.557-1.84 k_{T} \text { for } 0.35 \leq k_{T} \leq 0.75 \\
0.177 \text { for } k_{T}>0.75
\end{array}\right.
$$

These correlations eased the estimation of the skydiffuse component, $I_{\mathrm{d}}$, from the total irradiation, with the subsequent calculation of the beam irradiation, $I_{\mathrm{b}}$, as follows:

$$
I_{b}=I-I_{d}
$$

Calculation of the total irradiation on a tilted surface relies on the beam and sky-diffuse irradiation components along with the observed irradiance [35]:

$$
\begin{aligned}
I_{T}= & I_{b}\left(\frac{\cos \theta}{\cos \theta_{z}}\right)+I_{d}\left(\frac{1+\cos \beta}{2}\right) \\
& +I * \rho_{g}\left(\frac{1-\cos \beta}{2}\right) .
\end{aligned}
$$

The three terms in Equation 19 are the beam, skydiffuse, and ground-reflected components, respectively. The first parenthetical coefficient is the ratio of beam 
irradiation on a tilted plane with respect to that on a horizontal surface. The remaining parenthetical coefficients represent view factors of the sky and ground, respectively. The parameter, $\rho_{\mathrm{g}}$, is the diffuse reflectance or albedo which accounts for the ratio of insolation reflected by the ground. We adopted a two-tiered reflectance trend [61] with higher and lower albedo values [62] for December through March and April through November, respectively:

$$
\begin{aligned}
& \rho_{g}=\left\{\begin{array}{c}
0.5 \text { for } n \leq 91, n>335 \\
0.2 \text { for } 91<n \leq 335
\end{array}\right. \text { for perpetual years, } \\
& \rho_{g}=\left\{\begin{array}{c}
0.5 \text { for } n \leq 92, n>336 \\
0.2 \text { for } 92<n \leq 336
\end{array}\right. \text { for leapyears. }
\end{aligned}
$$

Liu and Jordan [35] relied on the empirical correlations of Cooper [55] for solar position angles. We utilized the correlations of Spencer and subsequently refer to this as the modified version (mL\&J). Duffie and Beckman described the isotropic diffuse model of Liu and Jordan as being easily understood, conservative in quantification, and relatively easy for the calculation of irradiation on tilted surfaces [54].

\section{Application of the models}

The modeling completed for this study revolved around the meteorological data from the ERS weather station. Those data included 1-h insolation values, $I$, as recorded with the year, Julian calendar day, $n$, and end-of-hour (standard) time, $h$. The geographic coordinates of the ERS provided the latitude $43.641^{\circ} \mathrm{N}(\phi)$, longitude $80.406^{\circ} \mathrm{W}\left(L_{\mathrm{LOC}}\right)$, and the corresponding standard time meridian of $75^{\circ}\left(L_{\mathrm{ST}}\right)$ for the solar position and insolation equations. We investigated a range of orientations by varying the slope $(\beta)$ and azimuth $(\gamma)$ in $15^{\circ}$ increments, from $0^{\circ}$ (flat) to $90^{\circ}$ (vertical) and $0^{\circ}$ (south) to $345^{\circ}$ ( $15^{\circ}$ east of south), respectively. We utilized the $K \& S$ and $m L \& J$ models to estimate the average insolation values for a typical year and periods representing each 3-month season, month, week, and hour.

Calculation of the extraterrestrial irradiation on a horizontal surface, $I_{0}$, with Equation 13 required hour angle values for the beginning $\left(\omega_{1}\right)$ and end $\left(\omega_{2}\right)$ of the observation period. The meteorological data provided the end-of-hour time, $h$, with the start-of-hour time having a value of $1 \mathrm{~h}$ less. Calculation of the corresponding values of $\omega_{2}$ and $\omega_{1}$ relied on Equations 6 and 7. We limited the calculation of the irradiation on inclined surfaces to periods during which the zenith angle was less than $80^{\circ}$ [61-64].

In this study, we relied on the classic solar position equations for the $K \& S$ model. This model provides estimates of the instantaneous irradiation $\left(\mathrm{W} / \mathrm{m}^{2}\right)$, which we multiplied by $1 \mathrm{~h}$ to obtain the corresponding insolation values $\left(\mathrm{Wh} / \mathrm{m}^{2}\right)$. We utilized mid-hour values of the hour angle $(\omega)$ to more accurately represent the values associated with the measurement period of insolation data. We refer to this model as a 'clear-sky' model as it relies solely on artificial data with the time values corresponding to those from the meteorological data.

The application of the mL\&J model in this study took two distinct forms. The first followed the equations provided in the 'Solar position, orientation, and extraterrestrial irradiation/insolation equations' and 'The mL\&J model' sections, while the second utilized a clear-sky assumption that equated the global horizontal irradiation, $I$, with the extraterrestrial irradiation, $I_{0}$. This assumption set the clearness index, $k_{T}$, to 1 and held the relation between the beam and sky-diffuse components of insolation in Equation 17 constant. We refer to the former and latter as the 'real-sky' and 'clear-sky' mL\&J models, respectively.

Duffie and Beckman [54] stated that the Julian calendar day, $n$, should be between 1 and 365 days, indicating limitations to a perpetual year. The inclusion of leap year data in this study required the extension of the applicable range by 1 day: $1 \leq n \leq 366$. Additionally, Duffie and Beckman [54] indicated that the use of integer values of $n$ is sufficient for engineering calculations but recognized the potential of using non-integer values. We used integer values for the hour, $h$, and Julian calendar day, $n$.

\section{Assessment strategies for community-scale potential}

This upper-limit estimate of solar energy potential by rooftop-mounted, city-wide arrays involved making several assumptions regarding coverage, siting constraints, and environmental factors. We assumed unrestricted availability of all rooftops and ignored existing rooftop penetrations and/or equipment, as well as structural limitations and ordinances that would preclude placement. We assumed that the panels would remain unshaded throughout the day and ignored the impact of shadows (hard or soft [65]) cast by adjacent trees, buildings, and freestanding structures. We disregarded the influence of ambient temperature.

We followed two strategies for rooftop area estimation. The first viewed all rooftops as horizontal planes, which allowed us to equate the available solar collection area with the cumulative footprint of Guelph's building. This horizontal plane assumption disregards the variation that exists among rooftop design with respect to shape, segmentation, orientation, and slope. The City of Guelph GIS data [51] included a parcel layer with zoning classifications [53] that indicated the types of buildings present. We divided this layer into several new layers by selecting and extracting the parcels according to their classification. The new parcel layers allowed us to utilize the clip function to subsequently create building layers 
for each classification. We computed footprint values from these layers using the ArcMap field calculator.

A review of orthographic photographs covering Guelph [66] showed that commercial, industrial, and institutional structures typically had rooftops which appeared to be horizontal, while residential, agricultural, and park buildings varied considerably. The second strategy utilized these findings and applied the horizontal plane assumption to the first group (A) while attempting to make concessions for the variation associated with the latter (B). For the group B buildings, we utilized a composite insolation and rooftop area value. This value accounted for an increase in rooftop surface area with respect to building footprint as well as the corresponding increase in insolation. To do this, we multiplied the insolation values for a specific orientation and slope with the trigonometric ratio corresponding to the latter. We then averaged these values to obtain a composite insolation and rooftop area value. The composite value utilized slopes, $\beta$, ranging from $0^{\circ}$ to $75^{\circ}$, and azimuth angles, $\gamma$, ranging from $0^{\circ}$ to $345^{\circ}$, both in $15^{\circ}$ increments, with equal weighting for each combination. The basis of our assumption of equal weighting for was twofold. First, the orthographic photographs [66] show that Guelph's layout does not follow a grid pattern with a unique orientation. Second, we included a broad range of slopes and assumed that the average would adequately represent the variation present within the community.

These assumptions and strategies simplified the solar energy estimate by foregoing independent evaluations of each building. We viewed these strategies as near upperlimit estimates while recognizing that actual production should be lower as a result of the previously mentioned constraints for which we made assumptions. To estimate the community's rooftop insolation, we multiplied the cumulative rooftop area by the insolation values, with the inclusion of the surface area and orientation adjustment for the second strategy. Finally, we applied the efficiencies of the chosen systems to obtain the rooftopmounted solar energy potential for the respective systems in Guelph.

\section{Results and discussion}

The goal of this study was to assess the local solar energy potential available to the community of Guelph with the use of PV and HW panels. This assessment involved insolation data from different sources. We gathered data for the city from two solar atlases and applied meteorological data to several models. The latter afforded a great deal of flexibility with respect to evaluating the impact of variation in planar surface orientation. The atlases provided a basis of comparison of the obtained results and validated our application of the models. The final evaluation combined the resource estimates and the efficiency of commercially available systems with the rooftop assessment strategies. This section brings together those components and describes the results obtained for this city-scale solar energy resource assessment.

We reviewed the ERS insolation data ('Meteorological station data' section) prior to their use and found that $98.9 \%$ of the data for the 21-year period was applicable (i.e., a loss of 2,179 hourly observations). The majority of the lost observations resulted from three major outages spanning 30 days in September 2003, 13 in October 2006, and 35 in March through May 2009. These outages account for 715,294 , and 850 observations, respectively, explaining $85.3 \%$ of the unusable data, with the remainder resulting from minor outages, erratic observations, or duplication. We assumed that the lost data would either lead to conservative results for daytime observations or be irrelevant for those occurring at night (i.e., negligible insolation). As such, we accepted the loss of data for the evaluated periods (i.e., annual, 3-month seasons, monthly, weekly, and hourly).

The application of the K\&S [34] and mL\&J [35] models in this study led to three sets of results. The K\&S model represents a clear-sky scenario that excludes meteorological observations and relies on simulated insolation data. As described in the 'Application of the models' section, this study relied on two versions of the mL\&J model. The clear-sky mL\&J model used simulated data, representative of extraterrestrial insolation, while the real-sky mL\&J model incorporated local meteorological data. All models relied on the standard time hour values of the meteorological data. We evaluated results of beam (B) and sky-diffuse (D) insolation for all three models and included the ground-reflected $(G)$ component with the mL\&J models. Our inclusion of the latter component disregards the impact of adjacent buildings, structures, etc.

The orientation of a solar panel has two components: the slope (incline or tilt), $\beta$, and the azimuth (deviation from due south, west positive), $\gamma$. The atlases only provided values for due-south $\left(\gamma=0^{\circ}\right)$ orientations [20,40]. Table 1 lists the mean daily global insolation results obtained from the various data sources for horizontal and vertical, south-facing surfaces $\left(\beta=0^{\circ}\right.$ and $\beta=90^{\circ}$, $\gamma=0^{\circ}$, respectively) over several time periods. The K\&S and clear-sky mL\&J models typically exceeded the range of values obtained from those sources. The results from the real-sky mL\&J model most frequently fell within the range of values from the NRCan Interactive Maps [20] and National Atlas [40], with the balance being slightly conservative. The alignment of these values gave credibility to the application of the mL\&J model with the insolation data.

The application of the K\&S and mL\&J models allowed us to evaluate the insolation on surfaces with any 
Table 1 Comparison of mean daily global insolation results

\begin{tabular}{|c|c|c|c|c|c|c|c|c|}
\hline \multirow[t]{3}{*}{ Month } & \multirow[t]{3}{*}{ Beta (tilt) } & \multirow{3}{*}{$\begin{array}{c}\text { NRCan Interactive } \\
\text { Maps (2007) } \\
\text { Real sky } \\
\left(\mathrm{MJ} / \mathrm{m}^{2} / \text { day }\right)\end{array}$} & \multirow{3}{*}{$\begin{array}{c}\begin{array}{c}\text { National Atlas of } \\
\text { Canada (1984) }\end{array} \\
\begin{array}{c}\text { Real sky } \\
\left(\mathrm{MJ} / \mathrm{m}^{2} / \text { day }\right)\end{array}\end{array}$} & \multirow{3}{*}{$\begin{array}{l}\begin{array}{c}\text { Korsun and Stranix } \\
(1984)\end{array} \\
\frac{\frac{\text { Clear sky }\left(\mathrm{MJ} / \mathrm{m}^{2} / \text { day }\right)}{B+D}}{B+{ }^{2}}\end{array}$} & \multicolumn{4}{|c|}{$\begin{array}{l}\text { Modified Liu and } \\
\text { Jordan (1963) }\end{array}$} \\
\hline & & & & & \multicolumn{2}{|c|}{ Clear sky (MJ $/ \mathrm{m}^{2} /$ day) } & \multicolumn{2}{|c|}{ Real sky $\left(\mathrm{MJ} / \mathrm{m}^{2} /\right.$ day } \\
\hline & & & & & $B+D$ & Total & $B+D$ & Total \\
\hline \multirow[t]{2}{*}{ April } & Horizontal $\left(0^{\circ}\right)$ & 15 to 18 & 17 to 18 & 23.3 & 32.6 & 32.6 & 16.3 & 16.3 \\
\hline & Vertical $\left(90^{\circ}\right)$ & 9 to 12 & 11 to 12 & 13.6 & 18.2 & 21.59 & 8.89 & 10.6 \\
\hline \multirow[t]{2}{*}{ June } & Horizontal $\left(0^{\circ}\right)$ & 21 to 24 & 22 to 23 & 30.8 & 40.7 & 40.7 & 21.9 & 21.9 \\
\hline & Vertical $\left(90^{\circ}\right)$ & 9 to 12 & 8 to 9 & 7.41 & 11.2 & 15.3 & 7.53 & 9.72 \\
\hline \multirow[t]{2}{*}{ October } & Horizontal $\left(0^{\circ}\right)$ & 9 to 12 & 9 to 10 & 12.3 & 20.2 & 20.2 & 9.31 & 9.31 \\
\hline & Vertical $\left(90^{\circ}\right)$ & 9 to 12 & 11 to 12 & 17.8 & 24.9 & 26.9 & 9.00 & 9.93 \\
\hline \multirow[t]{2}{*}{ December } & Horizontal $\left(0^{\circ}\right)$ & 3 to 6 & 4 to 5 & 5.44 & 10.5 & 10.47 & 4.43 & 4.43 \\
\hline & Vertical $\left(90^{\circ}\right)$ & 6 to 9 & 7 to 8 & 14.2 & 23.7 & 26.2 & 6.67 & 7.76 \\
\hline \multirow[t]{2}{*}{ Annual } & Horizontal $\left(0^{\circ}\right)$ & 12 to 15 & 13 to 14 & 17.8 & 25.9 & 25.9 & 13.5 & 13.5 \\
\hline & Vertical $\left(90^{\circ}\right)$ & 9 to 12 & 10 to 11 & 13.7 & 19.9 & 23.4 & 8.76 & 10.53 \\
\hline
\end{tabular}

Horizontal and vertical, south-facing surfaces: $\beta=0^{\circ}$ and $\beta=90^{\circ}, \gamma=0^{\circ}$, respectively. As obtained from the various data sources and models: interactive maps of the PV potential and solar resource of Canada - NRCan [20], the National Atlas of Canada [40], Korsun and Stranix [34] model, modified Lui and Jordan [35] model; clear and real sky (with insolation data); values for the models indicated as sums of beam and diffuse (B + D).

orientation. With that capacity, we modeled planar surfaces at orientations in $15^{\circ}$ increments from horizontal to vertical $\left(\beta=0^{\circ}\right.$ to $\left.90^{\circ}\right)$ and full circle from due south $\left(\gamma=0^{\circ}\right)$. We archived results for 145 orientations for time periods representing a typical year, each 3-month season, month, week, and hour. We present schematic diagrams of the annual results in a format that we refer to as a 'sunflower.' We defined the sunflower as a radial plot representing the variation of insolation on planar surfaces as a function of orientation and inclination. The reference value for each sunflower is the sum of the beam and sky-diffuse $(B+D)$ insolation on the horizontal plane. This value is independent of the azimuth and excludes the ground-reflected $(G)$ component due to its orientation. The creation of such diagrams with various site data has the potential to provide insight into insolation trends resulting from regional meteorology. The concept is similar to that of Christensen and Barker [67], whose work included contour plots relating the deviation from optimal orientation and the associated proportion of insolation losses. This paper includes several sunflower diagrams created from the results obtained with the mL\&J models.

Figure 5 is the $\mathrm{B}+\mathrm{D}$ sunflower created from the results of the clear-sky mL\&J model and represents the extraterrestrial insolation of an average year with a reference (horizontal) value of $8,290 \mathrm{MJ} / \mathrm{m}^{2} /$ year. The figure shows east to west symmetry and that under simulated clear-sky conditions, panels facing due south $\left(\gamma=0^{\circ}\right)$ would receive the most insolation, with those facing due north $\left(\gamma=180^{\circ}\right)$ receiving the least. This result met expectations and provided additional credibility to the application of the mL\&J model and insolation data. Furthermore, this finding did not indicate a time bias associated with the lost meteorological observations. This sunflower also indicates that under simulated conditions, an optimum would occur for a south-facing panel with an incline $(\beta)$ between and/or near $30^{\circ}$ and $45^{\circ}$.

Figure 6 is a sunflower obtained with the real-sky mL\&J results and has a reference value of $4,310 \mathrm{MJ} / \mathrm{m}^{2}$ / year. This value is almost $50 \%$ less than that of the clearsky mL\&J model and indicates the impact of atmospheric and meteorological conditions on insolation. Contrary to the common assumption, this figure shows that the real-sky optimum deviates from due south. The optimum azimuth for the real-sky model occurred between $345^{\circ}$ and $330^{\circ}\left(15^{\circ}\right.$ and $30^{\circ}$ east of south, respectively) with a slope of $c a .30^{\circ}$. Interestingly, there is minimal variation between the insolation values for surfaces with slopes between $15^{\circ}$ and $45^{\circ}$ and azimuths ranging from $315^{\circ}$ to $360^{\circ}\left(0^{\circ}\right)$.

Figure 7 provides diurnal trends of $\mathrm{B}+\mathrm{D}$ insolation on surfaces with an incline of $30^{\circ}$ and azimuth angles of $0^{\circ}$ and $345^{\circ}$ as obtained with the real-sky mL\&J model. This figure excludes the ground-reflected component which represented, at most, $2 \%$ of the total. The beam component dominated the insolation for most of the day with a peak occurring around noon (standard time). This corresponds to the period between 11 a.m. and noon as the time designations represent end-of-hour observations. The sky-diffuse component exhibited a broad peak that occurred from noon (12:00 p.m.) through 1400 hours (2:00 p.m.) standard time. Following that period, a transition of dominance from the beam to the skydiffuse component occurred, with the latter eclipsing the prior by 1700 hours (5:00 p.m.). As shown, the beam components dominate the insolation for the orientations 


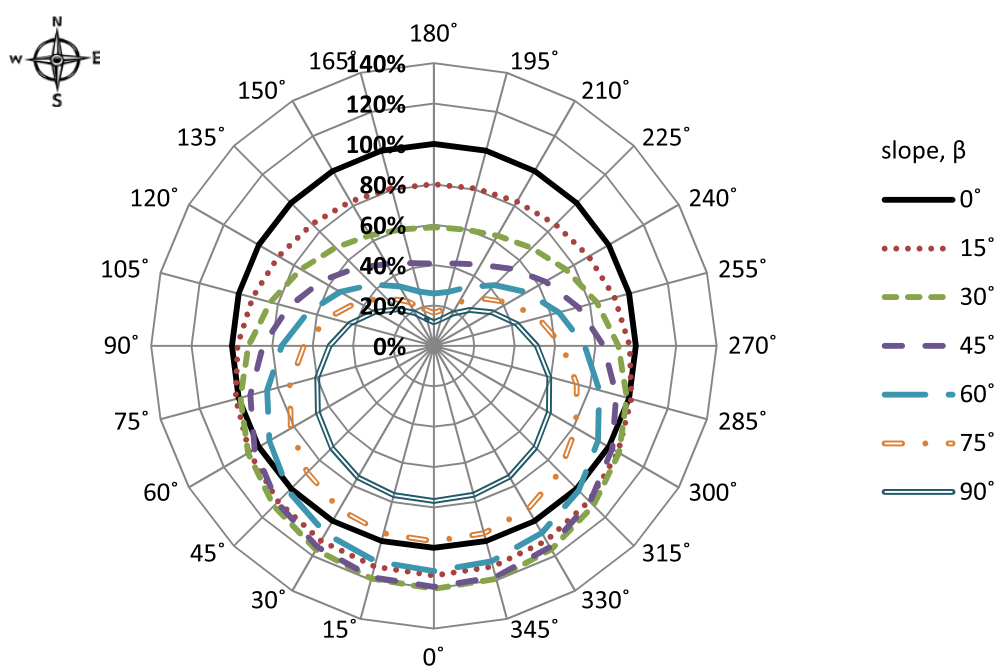

Figure 5 The annual beam and diffuse radiation sunflower based on the clear-sky results. Obtained with the modified Liu and Jordan model [35] and ERS data. B + D insolation of $8,290 \mathrm{MJ} / \mathrm{m}^{2} /$ year for a horizontal surface.

shown. The insolation for a panel facing just east of south $\left(\gamma=345^{\circ}\right.$ or $\left.-15^{\circ}\right)$ surpasses that for one facing due south $\left(\gamma=0^{\circ}\right)$ from morning till noon at which point the trend reverses. Surfaces facing east or west of south $\left(\gamma<0^{\circ}\right.$ or $\gamma>0^{\circ}$, respectively) would be expected to show additional insolation during the morning or afternoon, respectively. The surface oriented slightly to the east received just over half of its total annual insolation during the morning, with the trend reversing for surface facing due south. The additional morning insolation on the surface oriented to the east contributed to a $1.0 \%$ advantage of the total annual insolation with respect to that facing due south.
Figure 8 is a real-sky mL\&J sunflower for surfaces with inclinations of $30^{\circ}$ and $90^{\circ}$ for $\mathrm{B}+\mathrm{D}$ insolation with and without the ground-reflected (G) component. The ground-reflected component depends only on the slope of the surface and is independent of the azimuth. This holds true for the sky-diffuse (D) insolation, as exemplified by the identical trends for this component in Figure 7, and is the result of the isotropic nature of the model [54]. The horizontal surface lacks groundreflected insolation, and the contribution of this component increased with surface slope, reaching a maximum at vertical $\left(\beta=90^{\circ}\right)$. This trend was inverted for the skydiffuse component, where vertical surfaces received

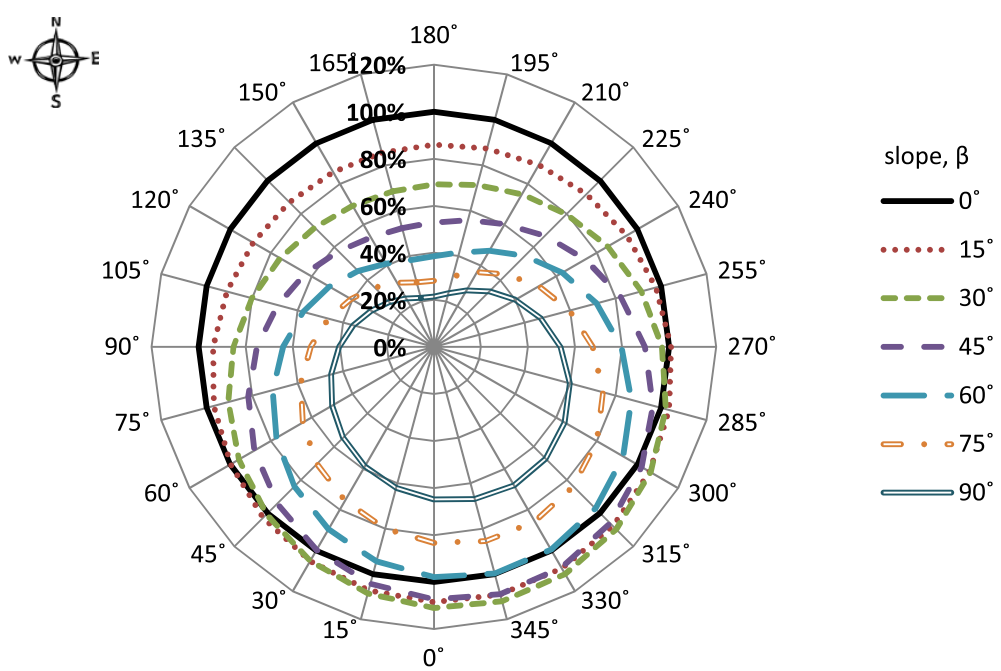

Figure 6 The annual beam and diffuse radiation sunflower based on the real-sky results. Obtained with the modified Liu and Jordan model [35] and ERS data. B + D insolation of $4,310 \mathrm{MJ} / \mathrm{m}^{2} /$ year for a horizontal surface. 


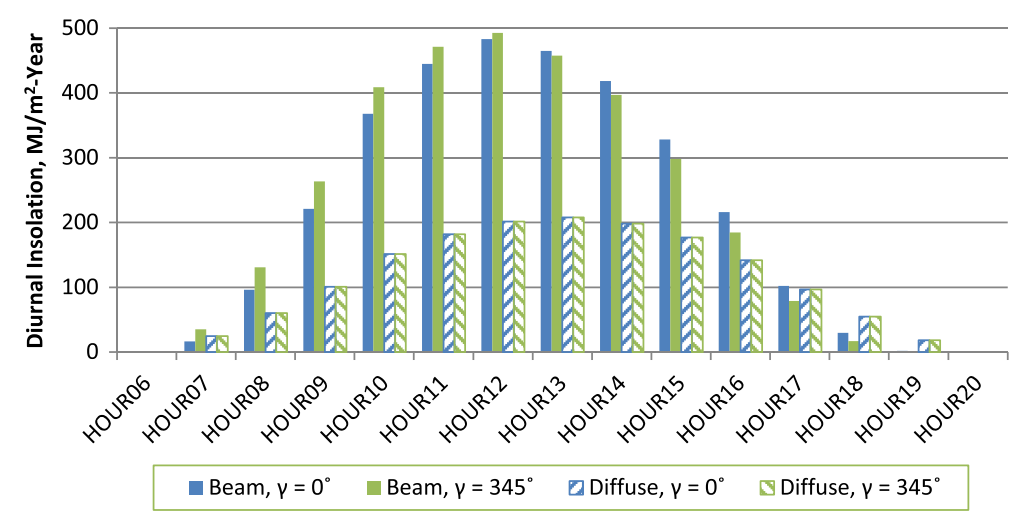

Figure 7 The annual beam, sky-diffuse, and ground-reflected components of the diurnal insolation. Based on real-sky results obtained with the modified Liu and Jordan model [35] and ERS data. For surfaces with a slope (tilt), $\beta$, of $30^{\circ}$ and azimuth angles (deviation from south), $\gamma$, of $0^{\circ}$ and $345^{\circ}$. B + D insolation values of 4,840 and $4,790 \mathrm{MJ} / \mathrm{m}^{2} / y$ ear for the respective orientations.

approximately half the amount of horizontal surfaces (results not shown). The results indicate the potential for surfaces inclined at $30^{\circ}$ and $90^{\circ}$ to respectively receive an additional 76 and $569 \mathrm{MJ} / \mathrm{m}^{2} /$ year from the $\mathrm{G}$ component. The magnitude of this potential depends on the assumed values of diffuse reflectance, $\rho_{\mathrm{g}}$, (see 'The mL\&J model' section) as applied to the real-sky $\mathrm{mL} \& \mathrm{~J}$ model.

The sunflowers provided visual representations of the variation of insolation with respect to orientation and indicated the presence of an optimum azimuth that was not due south. The search for the optimum orientation began with the real-sky mL\&J sunflower and continued with incremental analysis. We evaluated the annual potential for a fixed-position panel based on the B + D insolation which we attributed to rooftop-mounted panels in the absence of shadows cast by adjacent trees, buildings, and freestanding structures. We limited the optimization process to the results obtained for the annual average while recognizing that almost limitless scenarios exist for optimization with respect to other periods. The sunflower in Figure 6 (real-sky mL\&J model) indicated that the optimum south-facing orientation for B $+D$ insolation would occur for a panel with a tilt of approximately $30^{\circ}$. Additional modeling revealed that the south-facing optimum occurred for a tilt, $\beta$, of $28^{\circ}$ with $4,790 \mathrm{MJ} / \mathrm{m}^{2} /$ year of $\mathrm{B}+\mathrm{D}$ insolation. Changing this slope to $15^{\circ}$ or $45^{\circ}$ reduced this insolation by, at most, $3.5 \%$. The inclusion of the ground-reflected component for the panel inclined at $28^{\circ}$ could provide an additional $70 \mathrm{MJ} / \mathrm{m}^{2} /$ year of insolation. The sunflower in Figure 6 also indicated that the true optimum

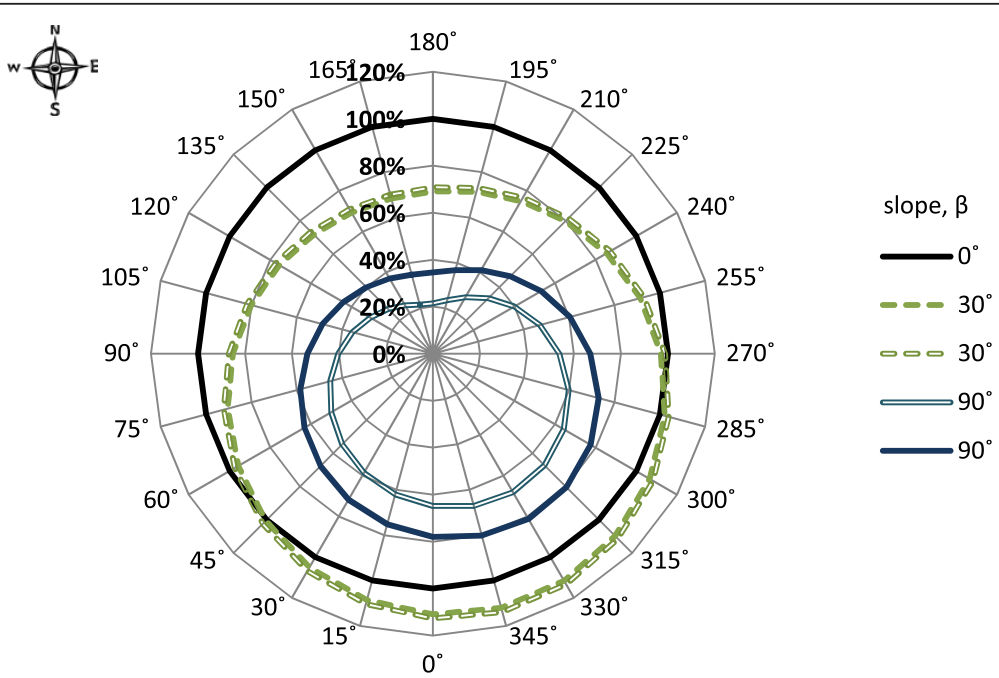

Figure 8 The annual beam and diffuse radiation sunflower with and without the ground-reflected radiation. Based on real-sky results obtained with the modified Liu and Jordan model [35] and ERS data. For surfaces of various orientations with slopes of $30^{\circ}$ and $90^{\circ}$. B $+D$ insolation values of $4,310 \mathrm{MJ} / \mathrm{m}^{2} / y e a r$ for a horizontal surface. 
would occur for a panel with tilt and azimuth angles of approximately $30^{\circ}$ and $345^{\circ}$, respectively, with 4,830 $\mathrm{M} / \mathrm{m}^{2} /$ year of $\mathrm{B}+\mathrm{D}$ insolation. We reviewed the adjacent orientations $\left( \pm 15^{\circ}\right.$ for $\beta$ and $\gamma$ ) from the sunflower diagram and found that reorientation led to modest penalties ranging from $0.4 \%$ to $4.2 \%$. Deviation from this optimum showed greater losses with changes to the slope than with the azimuth, with losses being compounded by simultaneous changes to both parameters. These results indicated the proximity of the true optimum to this orientation. Additional modeling revealed that the true $\mathrm{B}+\mathrm{D}$ optimum occurred for an azimuth of $342^{\circ}\left(18^{\circ}\right.$ east of south) and incline of $30^{\circ}$ with $4,840 \mathrm{MJ} / \mathrm{m}^{2} /$ year of $\mathrm{B}+\mathrm{D}$ insolation. This resulted in a $1 \%$ increase over the south-facing optimum, with the addition of the ground-reflected component providing another $70 \mathrm{MJ} / \mathrm{m}^{2} /$ year. Christensen and Barker [67] investigated insolation data for 239 sites in the USA and observed deviations of the optimum orientation from due south of this magnitude for several regions in the USA. They observed regions which exhibited deviation of the optimum from due south to the east and west variation and associated these with atmospheric trends (i.e., cloud cover, precipitation, etc.).

The modeling of meteorological data has an advantage over solar atlas results as it offers the ability to evaluate surfaces at any orientation. The obtained results (archived elsewhere) represent a great resource for those in the area who wish to utilize existing surfaces with orientations other than those currently available from public sources. This work is fundamental to the goal of estimating the solar energy potential in Guelph and applies to neighboring communities. Unfortunately, we found no timely manner by which to assess the characteristics of each rooftop. As such, the remainder of this assessment continued with assumptions regarding the building rooftops in this community (see the 'Assessment strategies for communityscale potential' section).

Table 2 lists annual insolation values obtained with the real-sky mL\&J model and those from the solar atlases. The first and last sections of the table focus on the values obtained for horizontal and vertical, south-facing surfaces, while the intermediate sections show those for the optimized orientations. In this and subsequent tables, we present only the annual values obtained from the NRCan Interactive Maps, noting their similarity to those from the National Atlas. The values shown for the NRCan Interactive Maps represent an average of the range extremes shown in Table 1. The real-sky mL\&J results show the potential for incremental gains through adjustment to optimized orientations. The modeling results are conservative with respect to those of the NRCan Interactive Maps by as much as $25 \%$ for the $B+D$ values.
Table 2 Annual insolation results obtained from data sources and modeling

\begin{tabular}{|c|c|}
\hline Orientation and data source & Annual insolation $\left(\mathrm{MJ} / \mathrm{m}^{2}\right)$ \\
\hline \multicolumn{2}{|l|}{ Horizontal $(\beta=0)$} \\
\hline Interactive maps of Canada & 4,930 \\
\hline$m L \&$ real sky B + D & 4,310 \\
\hline \multicolumn{2}{|c|}{ South-facing optimum tilt for $B+D\left(\beta=28^{\circ}, \gamma=0^{\circ}\right)$} \\
\hline$m L \&$ real sky B + D & 4,790 \\
\hline$m L \&$ real sky $B+D+G$ & 4,860 \\
\hline \multicolumn{2}{|c|}{ Fully optimized tilt and azimuth for $B+D\left(\beta=30^{\circ}, \gamma=342^{\circ}\right)$} \\
\hline$m L \&$ real sky B + D & 4,840 \\
\hline$m L \&$ real sky $B+D+G$ & 4,910 \\
\hline \multicolumn{2}{|l|}{ South-facing wall $\left(\beta=90, \gamma=0^{\circ}\right)$} \\
\hline Interactive maps of Canada & 3,830 \\
\hline$m L \&$ real sky B + D & 2,800 \\
\hline$m L \&$ real sky $B+D+G$ & 3,370 \\
\hline
\end{tabular}

As derived from values provided in Table 1 and from real-sky results obtained with the modified Liu and Jordan model [35] and ERS data, including the total (beam, diffuse, and ground-reflected; $B+D+G$ ) insolation.

Figures 9, 10, and 11 provide bar graphs of the seasonal, biweekly, and diurnal trends, respectively, for planar surfaces at several orientations. These figures allow for the discernment of time effects of B $+\mathrm{D}$ insolation on each surface with respect to each time frame. These figures show that the horizontal and south-facing inclined surfaces generally outperformed the southfacing vertical surfaces (i.e., walls). However, each of these figures shows periods during which the insolation on the south-facing walls approached those of the other orientations. Figure 9 shows that the greatest amount of insolation for horizontal and south-facing inclined surfaces occurred during summer, whereas the peak for the vertical surfaces occurred during spring. Seasonal variation was minimal (i.e., relatively constant) for southfacing walls but substantial for those that are horizontal or optimized. Figure 10 refines the trends from Figure 9 and shows the gradual increase in insolation on the horizontal and inclined surfaces which peaked at midyear (summer) during weeks 25 to 28 . The variation in insolation for the vertical surfaces shows relative stability with two broad peaks occurring between weeks 7 to 12 and 35 to 40. As shown, the results for vertical surfaces during the first and last weeks of the year were comparable to those of the inclined surfaces and surpassed that of a horizontal surface. The insolation for the last biweekly period (weeks 51 to 52 ) were relatively high when compared to those preceding and following (weeks 1 to 2 ) this period. These artificially high values resulted from the inclusion of days beyond a normal 14-day period at the end of the year. Figure 11 offers a variation of the trends shown in Figure 7 with orientations matching 


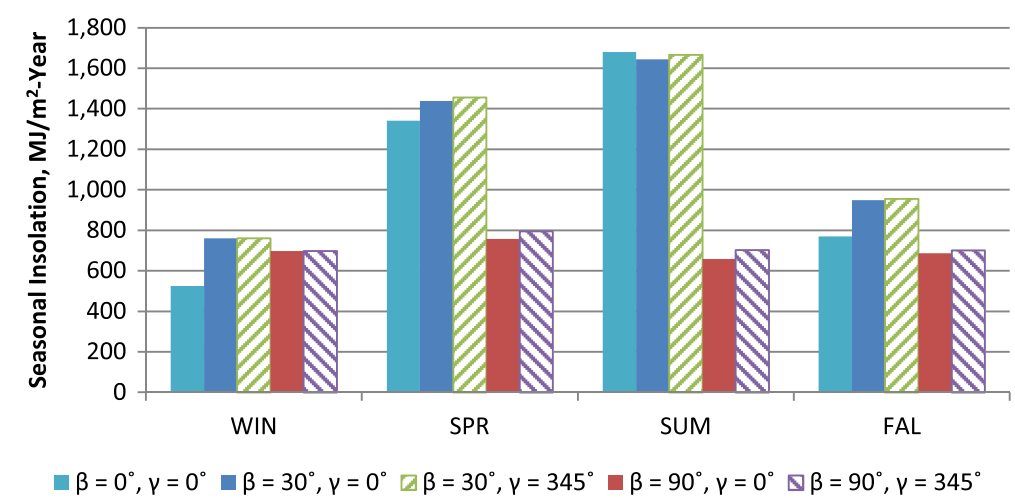

Figure 9 The seasonal contribution to the annual beam and sky-diffuse insolation on tilted surfaces. Based on real-sky results obtained with the modified Liu and Jordan model [35] and ERS data. For surfaces with slope (tilt) $\beta$ and azimuth angle (deviation from south) $\gamma$. B $+D$ insolation values of $4,310,4,790,4,830,2,800$, and $2,890 \mathrm{MJ} / \mathrm{m}^{2} /$ year for the respective orientations.

those of the previous two figures (Figures 9 and 10). As shown, the inclined and horizontal surfaces dominated throughout the day, with those tilted at $30^{\circ}$ having the advantage from 9:00 a.m. to 4:00 p.m. (1600 hours) standard time. Outside of this period, the horizontal surface received as much, if not more, $\mathrm{B}+\mathrm{D}$ insolation. As shown, the insolation reaching south-facing walls were relatively small, but not inconsequential. Figures 7 and 11 indicate the presence of a time-of-day bias associated with the shift of the optimum orientation from due south observed in Figure 6.

The next step of this assessment was the application of the insolation results to the city via theoretical community-scale arrays of either PV or HW systems. As discussed in the 'Solar PV system' and 'Solar HW system' sections, these relied on the performance characteristics of the SunPower E20/327 and Vaillant VFK 150 panels, respectively, with considerations for each BOS. The use of building footprint and zoning characterization data from an assembled GIS map provided the foundation for two evaluation scenarios based on rooftop-mounted panels. As described in the 'Assessment strategies for community-scale potential' section, the first scenario relied on the horizontal plane assumption which viewed all buildings as having horizontal rooftops and equated the available mounting area with that of each building's footprint. The second scenario utilized zoning characterization data and assumed a range of slopes and orientations for a subset of the buildings with the balance relying on the horizontal plane assumption.

Table 3 provides a summary of the solar energy potential with either of the described arrays to the roofs in Guelph given the respective scenarios. The table begins with the city's footprint area and that of its buildings. As shown, the buildings occupied approximately $10 \%$ of the city's land area. Orthographic photographs [66] showed that Guelph's commercial, industrial, and institutional structures (group A) typically had rooftops which appeared to be horizontal, while residential, agricultural, and park buildings (group B) varied considerably. Figure 12 shows the full composition of Guelph's buildings with the first group composing less than $40 \%$ of those structures and residences accounting for $60 \%$. The second section of Table 3 recaps the characteristics of the solar PV and HW systems. The remainder of the

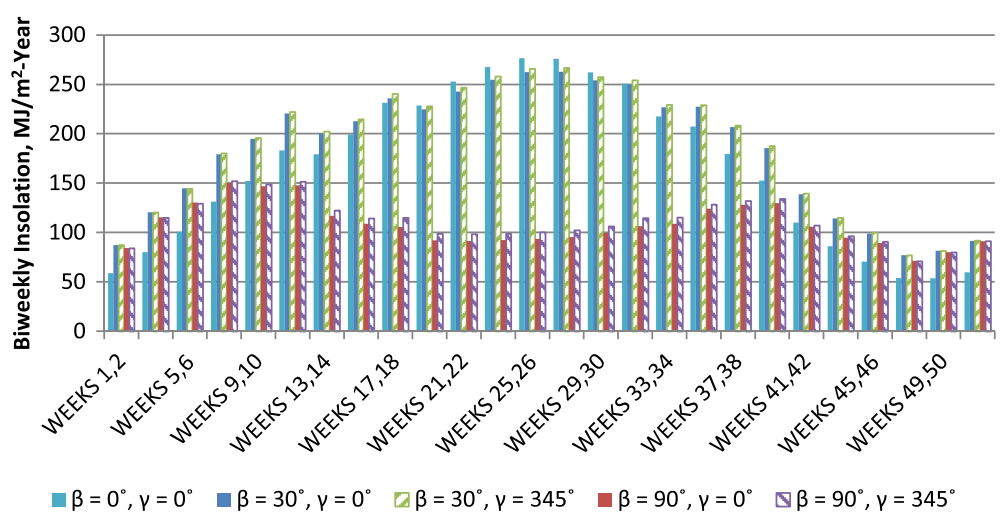

Figure 10 The biweekly contribution to the annual beam and sky-diffuse insolation on tilted surfaces. Please refer to notes from Figure 9 . 


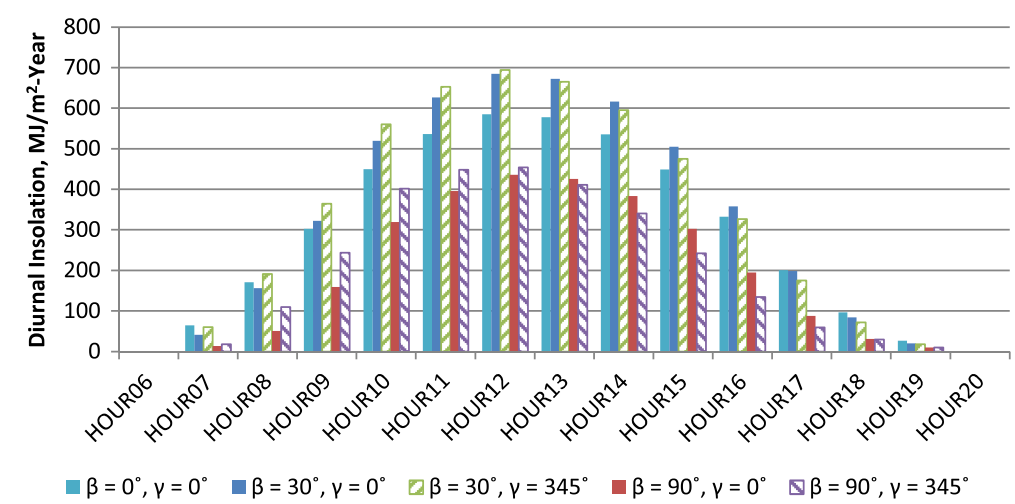

Figure 11 The diurnal contribution to the annual beam and sky-diffuse insolation on tilted surfaces. Please refer to notes from Figure 9 .

table provides the potential energy for the respective systems and scenarios, with the associated number of panels. The results for the first scenario (horizontal plane assumption) show that the differences in results from the data sources translate linearly when applied to the city scale. The second scenario (roof categorization assumption) yielded results that almost double those from the first for the respective technologies. The results for the second scenario include a breakdown of the contribution with respect to rooftop categorization (see the 'Assessment strategies for community-scale potential' section). The group B buildings accounted for $c a .80 \%$ of the energy potential due to the

Table 3 Summary of annual solar energy potential with community-scale arrays of PV or HW systems

\begin{tabular}{|c|c|c|c|}
\hline & \multirow[t]{2}{*}{ City of Guelph } & \multicolumn{2}{|c|}{ Manufacturer and model } \\
\hline & & SunPower E19/320 & Vaillant VFK 150 \\
\hline \multicolumn{4}{|l|}{ Footprint area } \\
\hline City footprint $\left(\mathrm{km}^{2}\right)^{\mathrm{a}}$ & 86.72 & & \\
\hline Cumulative building footprint area $\left(\mathrm{km}^{2}\right)^{\mathrm{b}}$ & 8.28 & & \\
\hline Commercial, industrial, and institutional (A) & 3.17 & & \\
\hline Residential, agricultural, and park (B) & 5.11 & & \\
\hline \multicolumn{4}{|l|}{ Characteristics } \\
\hline Rated efficiency ${ }^{c}$ & & $20.1 \%$ & $60 \%$ \\
\hline Balance-of-system efficiency & & $75 \%$ & $90 \%$ \\
\hline Per panel footprint $\left(\mathrm{m}^{2}\right)$ & & 1.63 & 2.50 \\
\hline \multicolumn{4}{|l|}{ First scenario - horizontal plane assumption } \\
\hline \multicolumn{4}{|l|}{ Annual potential energy production $\left(\mathrm{GWh}_{[\mathrm{e}]}\right)$} \\
\hline Interactive maps of Canada & & 1,709 & 6,120 \\
\hline$m L \&$ real sky B + D & & 1,496 & 5,360 \\
\hline \multicolumn{4}{|l|}{ Number of panels } \\
\hline Horizontal (footprint multiplier: 1.00) & & $5,090,000$ & $3,320,000$ \\
\hline \multicolumn{4}{|l|}{ Second scenario - roof categorization assumption } \\
\hline \multicolumn{4}{|l|}{ Annual potential energy production $\left(\mathrm{GWh}_{[\mathrm{e}]}\right)$} \\
\hline mL\& real sky B + D, horizontal $(A)$ & & 573 & 2,050 \\
\hline$m L \&$ real sky $B+D$, variable $(B)$ & & 2,380 & 8,530 \\
\hline Total (A and B) & & 2,950 & 10,580 \\
\hline \multicolumn{4}{|l|}{ Number of panels } \\
\hline Horizontal (footprint multiplier: 1.00) (A) & & $1,946,000$ & $1,269,000$ \\
\hline Varied (footprint multiplier:1.89, averaged) (B) & & $5,910,000$ & $3,860,000$ \\
\hline Total (A and B) & & $7,860,000$ & $5,120,000$ \\
\hline
\end{tabular}

(A) and (B) refer to the rooftop categorizations; 'Statistics Canada [25]; ' City of Guelph [51,53]; ' see the 'Solar PV system' and 'Solar HW system' sections. 


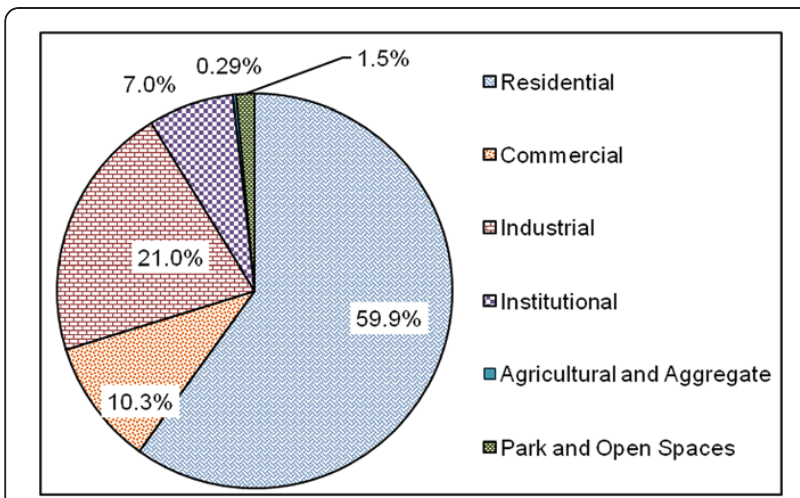

Figure 12 The composition of the City of Guelph's cumulative building footprint area. Data from the City of Guelph [51,53]. Building and rooftop categorizations: (A) commercial, industrial, and institutional; (B) residential, agricultural and aggregate, and park and open spaces.

compounded increase in rooftop area (via footprint multiplier) and B + D insolation. Although the potential energy from the respective scenarios almost doubled, the required number of panels increased by only $54 \%$. This result points to the significance of how and where such panels are employed.

Table 4 compares the annual solar energy potential from Table 3 with Guelph's 2005 demand, as provided by Garforth International. That document estimated the city's demand for 2005 including net electricity (i.e., following conversion, transmission, and distribution losses) and fuels [27]. The inclusion of several fuels in the energy use portfolio forced an interpretation of which applied to heating. We attributed those of natural gas, oil, and wood to this use. The energy values shown in the remaining two sections represent the 2005 demand for heat and net electricity. Covering Guelph's rooftops with HW panels could provide more heat than that used with the first and second scenarios showing the potential to respectively double or quadruple that amount. The alternative of using PV panels could almost meet or double the electricity demand, depending on the respective scenarios. Again, the group B buildings, of which $97 \%$ are residential, account for most of the potential from the respective arrays of the second scenario. These values indicate the potential based on the assumptions made in this study and represent the composition extremes of a solar energy array that would likely consist of both technologies. The use of rooftopmounted solar energy collectors on residential buildings has the potential for a large impact on Guelph's energy supply.

Overall, these results provide a favorable perspective of solar energy potential with respect to historic energy demand for the City of Guelph. The goal of this work was to obtain an upper-limit estimate of the use of this resource with commercially available technologies. The assessment relied on assumptions and two scenarios which formed

Table 4 Comparison of rooftop-mounted solar energy potential with estimate of Guelph's 2005 energy use

\begin{tabular}{|c|c|c|c|}
\hline \multirow{2}{*}{$\begin{array}{l}\text { Demand }\left(\mathrm{GWh}_{[\mathrm{e}]}\right) \text { and relative potential } \\
\text { for Guelph, } 2005\end{array}$} & \multirow[t]{2}{*}{ City of Guelph } & \multicolumn{2}{|c|}{ Manufacturer and model } \\
\hline & & SunPower E19/320 & Vaillant VFK 150 \\
\hline Total energy & $6,034^{a}$ & & \\
\hline \multicolumn{4}{|l|}{ First scenario - horizontal plane assumption } \\
\hline Interactive maps of Canada (\%) & & 28.3 & 101.5 \\
\hline$m L \&$ real sky B + D (\%) & & 24.8 & 88.8 \\
\hline \multicolumn{4}{|c|}{ Second scenario - roof categorization assumption } \\
\hline$m L \&$ real sky B + D (A and B) (\%) & & 49.0 & 175.4 \\
\hline Heat & $2,661^{\mathrm{a}}$ & & \\
\hline \multicolumn{4}{|l|}{ First scenario } \\
\hline National Atlas of Canada (\%) & & N/A & 230 \\
\hline mL\& real sky B + D (\%) & & N/A & 201 \\
\hline \multicolumn{4}{|l|}{ Second scenario } \\
\hline$m L \&$ real sky $B+D(A$ and $B)$ & & N/A & 398 \\
\hline Electricity & $1,630^{\mathrm{a}}$ & & \\
\hline \multicolumn{4}{|l|}{ First scenario } \\
\hline National Atlas of Canada (\%) & & 104.9 & N/A \\
\hline mL\& real sky B + D (\%) & & 91.8 & N/A \\
\hline \multicolumn{4}{|l|}{ Second scenario } \\
\hline$m L \&$ real sky $B+D(A$ and $B)(\%)$ & & 181.3 & N/A \\
\hline
\end{tabular}

aGarforth International LLC [27]; (A) and (B) refer to the rooftop categorizations; N/A, not applicable. 
the basis of evaluation for the solar PV and HW arrays. We employed these as strategies for dealing with uncertainty relating to rooftop orientation (both slope and azimuth) and the associated distribution.

There are additional factors that could increase or decrease the actual potential for the city. Other studies have gone along different lines regarding assumptions to perform such an estimate. A study by Wiginton et al. [22] assumed that shading would result in the exclusion of $70 \%$ of the total available area for the use of rooftopmounted PV systems. The application of their exclusion factor to this study would reduce the rooftop-mounted PV potential for Guelph to $54 \%$ of the 2005 electricity demand, assuming the second scenario. This does not take into account the exclusion of inclined north-facing rooftops [22] which are typically avoided for economic reasons but, as shown in this study, exhibited potential. The roof of each structure has various details relating to orientation, segmentation, shading, and penetrations that alter the area available and period of insolation. Although these require assessment on a case-by-case basis, strategies exist for incorporating details of shading losses with LiDAR (e.g., Nguyen and Pearce [24]). There is the potential to use existing surfaces, including walls, via mounting or modification with commercially available or forthcoming technologies including PV noise barriers [61], parking canopies, solar shingles, windows, and paints. For systems in high latitudes, there is the option of attaching booster reflectors to panels $[62,68]$. There are azimuth or dual-axis tracking systems that adjust panel orientation and follow the Sun in the sky while minimizing the angle of incidence, $\theta$, and maximizing beam insolation. There are also technologies that utilize different or multiple spectrums of light and/or heat that could change the paradigm of energy conversion (e.g., Johnson thermoelectric energy converter [69]). There are differences between resource availability and demand over various time scales that make infrastructure essential to the expansion and use of renewable energy. These topics relate to ongoing work in areas of energy-use demand reduction, large-scale heat and electricity storage, and distribution and systems control (e.g., smart grids). This assessment relied on historic data, and future potential of solar technologies could be impacted by global climate change. The work of Crook et al. focused on the effects of climate change on surface temperatures along with direct and total insolation [70]. They noted that areas could expect increases or losses of potential depending on the solar technology employed. They also acknowledged that dust, wind, and precipitation could play important roles and require further investigation. These are factors for which we did not account.

This work met the primary goal of assessing the solar resource and corresponding energy potential with rooftop-mounted PV and HW panels based on commercially available systems for Guelph. The assessment utilized and combined a variety of data sources in several ways that offer strategies and scenarios that could transfer to other communities. The work concluded with a comparison of this potential with the city's historic energy use that showed that Guelph could do well by employing these technologies. The evaluation of the solar resource with the modeling of meteorological data led to the development of the sunflower diagrams, visual representations of insolation variation with respect to orientation and inclination. These diagrams could give users insight into the scale of the solar resource with respect to orientation and regional insolation trends. The potential use of solar energy in Guelph looks bright although there are a number of variables that would impact the scale of achievement with respect to this resource. Ultimately, as our energy supply and use paradigms continue to evolve, we must reassess and perhaps change how we do things while moving toward our potential.

\section{Conclusions}

1. The results indicated that coverage of all roofs in Guelph with SunPower E20/327 PV panels could provide the city with up to $2,950 \mathrm{GWh}$ of electricity, approaching double the 2005 electricity demand.

2. Similar coverage with Vaillant VFK 150 HW panels could provide up to $10,580 \mathrm{GWh}_{[\mathrm{e}]}$ of heat, almost quadruple the 2005 heating demand.

3. The results from the real-sky mL\&J closely matched the values provided by two solar resource atlases for horizontal and vertical, south-facing surfaces $\left(\beta=0^{\circ}\right.$ and $\beta=90^{\circ}, \gamma=0^{\circ}$, respectively) over several time periods.

4. The results from the clear-sky mL\&J model, which lacked the influence of atmospheric conditions and represented extraterrestrial insolation, overestimated the resource and indicated that a panel with a duesouth orientation would receive the most insolation.

5. The sunflowers (radial plots representing the variation of insolation on planar surfaces as a function of orientation) created for this study provide a new way of visualizing insolation results with respect to orientation.

6. The results from the real-sky mL\&J model showed that the optimum orientation deviated from due south, with the maximum insolation occurring for a panel oriented $18^{\circ}$ east of south with an incline of $30^{\circ}$.

7. A flat panel with this orientation could annually receive $4,840 \mathrm{MJ} / \mathrm{m}^{2}$ of beam and diffuse $(B+D)$ insolation based on the results with the real-sky mL\&J model. 
8. Deviation from the optimum positions by $15^{\circ}$ resulted in annual insolation values within 5\% of the maximum.

\section{Nomenclature}

$c$, empirical constant (0.357 - Equation 14); d, empirical constant (0.678 - Equation 14); $h$, standard-time hour of the day $(\mathrm{h}) ; k_{T}$, clearness index; $n$, integer Julian calendar day of the year (day); $B$, variance factor of extraterrestrial irradiation $\left({ }^{\circ}\right)$; B, beam insolation or irradiation; D, skydiffuse insolation irradiation; $E$, equation of time ( $\mathrm{min})$; $\mathrm{G}$, ground-reflected insolation or irradiation $\left(\mathrm{W} / \mathrm{m}^{2}\right)$; $G_{\mathrm{SC}}$, exoatmospheric solar constant $\left(1,353 \mathrm{~W} / \mathrm{m}^{2}\right)$; $G_{\mathrm{O}}$, extraterrestrial irradiation on a horizontal surface $\left(\mathrm{W} / \mathrm{m}^{2}\right) ; G_{\mathrm{ON}}$, extraterrestrial irradiation on the plane normal to solar radiation $\left(\mathrm{W} / \mathrm{m}^{2}\right) ; G_{\mathrm{OS}}$, apparent solar flux due to scatter $\left(214 \mathrm{~W} / \mathrm{m}^{2}\right.$ - Equation 14); $I$, total/global irradiance or solar irradiation on a horizontal surface $\left(\mathrm{MJ} / \mathrm{m}^{2}\right) ; I_{\mathrm{b}}$, beam (direct) irradiance or solar irradiation on a horizontal surface $\left(\mathrm{MJ} / \mathrm{m}^{2}\right)$; $I_{\mathrm{d}}$, skydiffuse irradiance or solar irradiation on a horizontal surface $\left(\mathrm{MJ} / \mathrm{m}^{2}\right) ; I_{\mathrm{D}}+\mathrm{s}$, beam (direct) and sky-diffuse irradiation on a horizontal plane $\left(\mathrm{W} / \mathrm{m}^{2}\right) ; I_{\mathrm{O}}$, extraterrestrial irradiation on a horizontal surface $\left(\mathrm{MJ} / \mathrm{m}^{2}\right) ; I_{\mathrm{T}}$, total (beam, sky-diffuse, and ground-reflected) insolation on a tilted plane $\left(\mathrm{W} / \mathrm{m}^{2}\right) ; I_{\mathrm{T}, \mathrm{D}}+\mathrm{S}$, beam (direct) and sky-diffuse insolation on a tilted plane $\left(\mathrm{W} / \mathrm{m}^{2}\right) ; L_{\mathrm{LOC}}$, site longitude ( ${ }^{\circ}$, west); $L_{\mathrm{ST}}$, local time-zone meridian ( ${ }^{\circ}$, west); $T_{\mathrm{S}}$, solartime hour of the day (h); $\beta$, surface slope (incline or tilt) angle relative to horizontal plane (flat $0^{\circ}$, wall $\left.90^{\circ} ;{ }^{\circ}\right) ; \gamma$, azimuth angle, deviation from due south (south $0^{\circ}$; west positive, northern hemisphere; ${ }^{\circ}$; $\delta$, declination angle, variation of Earth's polar axis $\left(^{\circ}\right) ; \theta$, angle of incidence relative to the normal of an tilted plane $\left({ }^{\circ}\right) ; \theta_{z}$, zenith angle of incidence relative to the normal of a horizontal plane $\left(^{\circ}\right)$; $\phi$, site latitude $\left(^{\circ}\right) ; \rho_{\mathrm{g}}$, diffuse reflectance of the total solar radiation; $\omega_{[i]}$, hour angle (time angle or angular dislocation; $\left.{ }^{\circ}\right) ; \omega_{\mathrm{S}}$, sunrise/set hour angle $\left({ }^{\circ}\right)$.

\section{Abbreviations}

AM: air mass (spectral irradiance); BOS: balance of system; CEP: community energy plan; ERS: Elora Research Station; GIS: geographic information system; HW: hot water; K\&S: Korsun and Stranix (model); mL\&: modified Liu and Jordan (model); NRCan: Natural Resource Canada; PR: performance ratio (overall); PV: photovoltaic.

\section{Competing interests}

The author declares that he has no competing interests.

\footnotetext{
Acknowledgements

The author gratefully acknowledges the financial support of the NSERC (Canada) Chairs in Environmental Design Engineering held by Professor Warren Stiver. The author gratefully acknowledges and thanks Professor Stiver for the project advice. The author also thanks Professor Stiver for attributing the term 'sunflower' to the schematic concept envisioned and created by the author. The author also thanks the staff of the Data Resource Centre at the University of Guelph for their assistance and especially that of Teresa Lewitzky. The author also thanks Assistant Professor W. David Lubitz for providing additional insight. In addition, the author thanks the
}

anonymous reviewers for providing insight and suggestions for the improvement of this article.

Received: 27 July 2012 Accepted: 24 October 2012 Published: 27 November 2012

\section{References}

1. Energy Information Administration (2011) International energy outlook 2011. http://www.eia.gov/forecasts/ieo/pdf/0484(2011).pdf. Accessed 6 Jan 2012

2. Williams DR (2010) Earth fact sheet. NASA. http://nssdc.gsfc.nasa.gov/ planetary/factsheet/earthfact.html. Accessed 6 Jan 2012

3. Pidwirny M (2010) Fundamentals of physical geography, 2nd edn http://www.physicalgeography.net/. Accessed 3 Aug 2010

4. Nishimura K (2012) Grassroots action for renewable energy: how did Ontario succeed in the implementation of a feed-in tariff system? Energ Sust \& Soc 2:6

5. Sanders B, Boozman J, Bingaman J (2011) S.1108, 10 Million Solar Roofs Act of 2011, 112th Congress, 1st Session, United States Senate. http://thomas. loc.gov/cgi-bin/query/D?c112:1:/temp/ c112DkOowK. Accessed 6 Jan 2012

6. McDowell H, Williams DE et al (2010) Senate Bill 267 w/SA2. 145th General Assembly, Delaware Senate. http://legis.delaware.gov/LIS/lis145.nsf/ vwlegislation/52862341C4591AD4852576F800731BAA. Accessed 6 Jan 2012

7. Levy C, Williams S et al (2010) House Bill 10-1342, 67th General Assembly, State of Colorado. http://www.state.co.us/gov_dir/leg_dir/olls/sl2010a/ sl_344.htm. Accessed 6 Jan 2012

8. Government of Ontario (2009) Green Energy Act, S.O. 2009, CHAPTER 12 Schedule A. http://www.e-laws.gov.on.ca/html/statutes/english/ elaws_statutes_09g12 e.htm. Accessed 26 July 2012

9. McKeon JF, Smith B et al (2008) Bill S1303/A3062. State of New Jersey, 213th Legislature. http://www.njleg.state.nj.us/2008/Bills/S1500/1303_I1.PDF. Accessed 6 Jan 2012

10. Ontario Ministry of Public Infrastructure Renewal (2006) Growth Plan for the Greater Golden Horseshoe 2006. https://www.placestogrow.ca/index.php. Accessed 15 Dec 2011

11. St Denis G, Parker P (2009) Community energy planning in Canada: the role of renewable energy. Renew Sust Energ Rev 13(8):2088-2095

12. Beatley $T$ (2009) Envisioning solar cities: urban futures powered by sustainable energy. J Urban Technol 14(2):31-46

13. International Energy Agency (2005) Technical Synthesis Report Annexes 22 \& 33. Energy Efficient Communities \& Advanced Local Energy Planning (ALEP). Energy Conservation in Buildings and Community Systems, Faber Maunsell Ltd. http://www.ecbcs.org/docs/annex_22-33_tsr_web.pdf. Accessed 15 Dec 2011

14. Natural Resources Canada (2007) Community energy planning guide. http://canmetenergy.nrcan.gc.ca/buildings-communities/communities/ publications/700. Accessed 15 Dec 2011

15. Community Energy Association (British Columbia) (2006) A tool kit for community energy planning in BC. http://www.communityenergy.bc.ca/ community-energy-planning-toolkit-rev-2006. Accessed 15 Dec 2011

16. ESRI (2012) Geographic Information Systems: Why Use GIS? http://www.gis com/content/why-use-gis. Accessed 25 May 2012

17. ESRI (2012) Geographic Information Systems: What is GIS? http://www.gis. com/content/what-gis. Accessed 25 May 2012

18. Van Hoesen J, Letendre S (2010) Evaluating potential renewable energy resources in Poultney, Vermont: a GIS-based approach to supporting rural community energy planning. Renew Energ 35(9):2114-2122

19. Canadian Urban Institute (2010) Integrated Energy Mapping For Ontario Communities. http://canurb.org/iemoc. Accessed 15 Dec 2011

20. Natural Resources Canada (2007) Photovoltaic potential and solar resource maps of Canada. http://pv.nrcan.gc.ca/. Accessed 11 Feb 2011

21. Liu G, Wu W, GE Q, Dai E, Wan Z, Zhou Y (2011) GIS-based assessment of roof-mounted solar energy potential in Jiangsu, China. In: Liu G, Wu W, GE Q, Dai E, Wan Z, Zhou Y (eds) Proceedings of the Second International Conference on Digital Manufacturing and Automation (ICDMA). IEEE, Zhangijiaje, pp 565-571

22. Wiginton LK, Nguyen HT, Pearce JM (2010) Quantifying rooftop solar photovoltaic potential for regional renewable energy policy. Comput Environ Urban 34(4):345-357

23. Hofierka J, Kaňuk J (2009) Assessment of photovoltaic potential in urban areas using open-source solar radiation tools. Renew Energ 34(10):2206-2214 
24. Nguyen HT, Pearce JM (2012) Incorporating shading losses in solar photovoltaic potential assessment at the municipal scale. Sol Energy 86(5):1245-1260

25. Statistics Canada (2012) Census subdivision of Guelph, CY - Ontario. http://www12.statcan.gc.ca/census-recensement/2011/as-sa/fogs-spg/Factscsd-eng.cfm?LANG=Eng\&GK=CSD\&GC=3523008. Accessed 14 Mar 2012

26. C.N. Watson and Associates Ltd (2003) City of Guelph household and population projections 2001-2027. Available via City of Guelph. http://guelph.ca/uploads/PBS_Dept/planning/documents/Forecast_final.pdf. Accessed 15 Dec 2011

27. Garforth International LLC (2007) City of Guelph community energy plan. Available via City of Guelph. http://guelph.ca/living.cfm?smocid=2127. Accessed 23 Mar 2009

28. Reindl DT, Beckman WA, Duffie JA (1990) Evaluation of hourly tilted surface radiation models. Sol Energy 45(1):9-17

29. Perez R, Ineichen P, Seals R, Michalsky J, Stewart R (1990) Modeling daylight availability and irradiance components from direct and global irradiance. Sol Energy 44(5):271-289

30. Hay JE, Davies JA (1980) Calculation of the solar radiation incident on an inclined surface. In: Hay JE, Won TK (eds) Proceedings of the First Canadian Solar Radiation Data Workshop. Supply and Services Canada, Toronto, pp 59-72

31. Kamali GA, Moradi I, Khalili A (2006) Estimating solar radiation on tilted surfaces with various orientations: a study case in Karaj (Iran). Theor Appl Climatol 84(4):235-241

32. Moon SH, Felton KE, Johnson AT (1981) Optimum tilt angles of a solar collector. Energy 6(9):895-899

33. Klein SA (1977) Calculation of monthly average insolation on tilted surfaces. Sol Energy 19(4):325-329

34. Korsun V, Stranix AJ (1984) Improving the match between the daily insolation peak and electrical peak demand. Sol Energy 22(2):171-174

35. Liu BYH, Jordan RC (1963) Rational procedure for long-term average performance of flat-plate solar energy collectors with design data for the U.S. its outlying possessions and Canada. Sol Energy 7(2):53-70

36. University of Guelph, Department of Plant Agriculture of Ontario Agricultural College - Stations (2011) Available via University of Guelph. http://www.uoguelph.ca/plant/stations/. Accessed 2 June 2011

37. University of Guelph, Department of Land Resource Science (2010) GTI monthly data files and ERS monthly data. In: Weather records for Elora Research Station \& Guelph Turfgrass Institute. Available via University of Guelph. http://agmet.Irs.uoguelph.ca/wxrecord/. Accessed 21 Jan 2010

38. Cros S, Mayer D, Wald D (2004) The availability of irradiation data, International Energy Agency. Report IEA-PVPS T2-04:2004 Version 3.0. http://www.risoe.dk/rispubl/NEl/nei-dk-4728.pdf. Accessed 11 Sept 2011

39. Pelland S, McKenney DW, Poissant Y, Morris R, Lawrence K, Campbell K, Papadopol P (2006) Development of photovoltaic resource maps for Canada. In: Proceedings of the 31st annual conference of the Solar Energy Society of Canada (SESCI). Montreal, 20-24 Aug 2006

40. International Energy Agency (2005) Trends in photovoltaic applications: survey report of selected IEA countries between 1992 and 2004. Report IEA-PVPS T1-14. http://www.risoe.dk/rispubl/NEl/nei-dk-4727.pdf. Accessed 29 May 2012

41. Natural Resources Canada (2006) Climate: Solar Radiation - Annual Map; Solar Radiation - December and June Map; Solar Radiation - April and October Map. In: The Atlas of Canada, 5th Edition, 1978 to 1995, The National Atlas of Canada, 5th edn. http://atlas.nrcan.gc.ca/site/english/maps/ archives/5thedition. Accessed 11 Feb 2011

42. SunPower Corporation (2011) E20/327 solar panel. http://us.sunpowercorp. com/homes/products-services/solar-panels/. Accessed 16 April 2012

43. International Electrotechnical Commission (2008) Photovoltaic devices - part 3: measurement principles for terrestrial photovoltaic (PV) solar devices with reference spectral irradiance data. Report IEC-60904-3 Ed 2.0 208-04, ISBN 2-8318-9705-X, Geneva, Available via www.iec.ch/. Accessed 12 Aug 2011

44. ASTM International (2008) ASTM Standard G173-03(2008): Standard tables for reference solar spectral irradiances: direct normal and hemispherical on $37^{\circ}$ tilted surface. ASTM, Conshohocken

45. Skoplaki E, Palyvos JA (2009) On the temperature dependence of photovoltaic module electrical performance: a review of efficiency/power correlations. Sol Energ 83(5):614-624

46. Branker K, Pathak MJM, Pearce JM (2011) Review of solar photovoltaic levelized cost of electricity. Renew Sust Energ Rev 15(9):4470-4482
47. Watt ME, Morgan R, Passey RJ (2006) Experiences with residential gridconnected photovoltaic systems in Australia, Technical report, Centre for Energy and Environmental Markets (CEEM). Sydney, Australia, University of New South Wales, http://www.ceem.unsw.edu.au/sites/default/files/uploads/ publications/WattMorganPasseySolar06_000.pdf

48. Leidl CM, Lubitz WD (2009) Comparing domestic water heating technologies. Technol Soc 31(3):244-256

49. Vaillant Ltd (2010) auroTHERM plus flat plate collectors. http://www.vaillant co.uk/installers/renewable-energy-1/solar-1/solar_system_range/aurothermplus/ [solar-brochure-2010.pdf]. Accessed 16 Oct 2011

50. United Nations Framework Convention on Climate Change, Small-Scale Working Group 07 (2006) Annex 3 - conversion factor for solar thermal collectors to determine eligibility limits. http://cdm.unfccc.int/Panels/ ssc_wg/. Accessed 16 Oct 2011

51. City of Guelph (2011) City of Guelph, Department of Information and Technology Services. City of Guelph municipal data, Guelph, Available via University of Guelph Library [Controlled Access]. Accessed 4 Mar 2012

52. ESRI (2005) ArcGIS 9 - ArcMap 9.1 [computer software]. ESRI, Redlands

53. City of Guelph (2012) Zoning by-law sections, 17-Feb, 2012. http://guelph.ca/living.ffm?itemid=46079\&smocid=1771. Accessed 2 Apr 2012

54. Duffie JA, Beckman WA (2006) Solar engineering of thermal processes, 3rd edn. Wiley, Hoboken

55. Cooper PI (1969) Absorption of solar radiation in solar stills. Sol Energy 12(3):333-346

56. Spencer JW (1971) Fourier series representation of the position of the Sun. Search 2(5):172

57. Duffie JA, Beckman WA (1974) Solar energy thermal processes. Wiley, New York

58. Meinel AB, Meinel MP (1976) Applied solar energy: an introduction. Addison-Wesley, Reading

59. Liu BYH, Jordan RC (1960) Interrelationship and characteristic distribution of direct, diffuse, and total solar radiation. Sol Energy 4(3):1-19

60. Orgill JF, Hollands KGT (1977) Correlation equation for hourly diffuse radiation on a horizontal surface. Sol Energy 19(4):357-359

61. Rocha J (2006) Economic and environmental evaluation of photovoltaic noise barriers. Thesis, The University of Guelph

62. Ross M, Royer JED (1999) Photovoltaics in cold climates. James \& James, London

63. Behr HD (1997) Solar radiation on tilted south oriented surfaces: validation of transfer-models. Sol Energy 61(6):399-413

64. Erbs DG, Klein SA, Duffie JA (1982) Estimation of the diffuse radiation fraction for hourly, daily, and monthly-average global radiation. Sol Energy 28(4):293-302

65. Mclntyre JH (2008) Photovoltaic potential in the City of Guelph. Guelph Eng J 1(1):24-26, Available via University of Guelph. http://www.soe.uoguelph. ca/webfiles/gej/contents.html. Accessed 7 May 2012

66. Ontario Ministry of Natural Resources (2010) South Western Ontario Orthophotography Project (2010). Peterborough, Ontario, http://www.grandriver.ca/swoop2010/. Accessed 15 Mar 2012

67. Christensen CB, Barker GM (2001) Effects of tilt and azimuth on annual incident solar radiation for United States locations. In: Proceedings of the solar forum 2001: solar energy: the power to choose. Washington, 21-25 Apr 2001

68. Rönnelid M, Karlsson B, Krohn P, Wennerberg J (2000) Booster reflectors for PV modules in Sweden. Prog Photovolt Res Appl 8(3):279-291

69. Ward L (2010) Shooting for the Sun. In: The Atlantic. http://www.theatlantic. com/magazine/archive/2010/11/shooting-for-the-sun/8268/. Accessed 13 Oct 2010

70. Crook JA, Jones LA, Forster PM, Crook R (2011) Climate change impacts on future photovoltaic and concentrated solar power energy output. Energy Environ Sci 4(9):3101-3109

doi:10.1186/2192-0567-2-23

Cite this article as: Mclntyre: Community-scale assessment of rooftopmounted solar energy potential with meteorological, atlas, and GIS data: a case study of Guelph, Ontario (Canada). Energy, Sustainability and Society 2012 2:23. 